\title{
On the strengthening and embrittlement mechanisms of an additively manufactured Nickel-base superalloy
}

\author{
Jinghao Xu ${ }^{\text {a }}$, Hans Gruber ${ }^{\mathrm{b}}$, Robert Boyd ${ }^{\mathrm{c}}$, Shuang Jiang ${ }^{\mathrm{a}}$, Ru Lin Peng ${ }^{\mathrm{a}}$, Johan J. Moverare ${ }^{\mathrm{a}, *}$ \\ ${ }^{a}$ Division of Engineering Materials, Department of Management and Engineering, Linköping University, Linköping SE-58183, Sweden \\ ${ }^{\mathrm{b}}$ Division of Materials and Manufacture, Department of Industrial and Materials Science, Chalmers University of Technology, Gothenburg SE-41296, Sweden \\ ${ }^{\mathrm{c}}$ Department of Physics, Chemistry and Biology, Linköping University, Linköping SE-58183, Sweden
}

\section{A R T I C L E I N F O}

\section{Keywords:}

Laser powder-bed-fusion

Nickel-base superalloy

Mechanical property

Cellular structure

$\gamma^{\prime}$ phase

\begin{abstract}
A B S T R A C T
The $\gamma^{\prime}$ phase strengthened Nickel-base superalloy is one of the most significant dual-phase alloy systems for hightemperature engineering applications. The tensile properties of laser powder-bed-fused IN738LC superalloy in the as-built state have been shown to have both good strength and ductility compared with its post-thermal treated state. A microstructural hierarchy composed of weak texture, sub-micron cellular structures and dislocation cellular walls was promoted in the as-built sample. After post-thermal treatment, the secondary phase $\gamma^{\prime}$ precipitated with various size and fraction depending on heat treatment process. For room-temperature tensile tests, the dominated deformation mechanism is planar slip of dislocations in the as-built sample while dislocations bypassing the precipitates via Orowan looping in the $\gamma^{\prime}$ strengthened samples. The extraordinary strengthening effect due to the dislocation substructure in the as-built sample provides an addition of $372 \mathrm{MPa}$ in yield strength. The results of our calculation are in agreement with experimental yield strength for all the three different conditions investigated. Strikingly, the $\gamma^{\prime}$ strengthened samples have higher work hardening rate than as-built sample but encounter premature failure. Experimental evidence shows that the embrittlement mechanism in the $\gamma^{\prime}$ strengthened samples is caused by the high dislocation hardening of the grain interior region, which reduces the ability to accommodate further plastic strain and leads to premature intergranular cracking. On the basis of these results, the strengthening micromechanism and double-edge effect of strength and ductility of Nickel-base superalloy is discussed in detail.
\end{abstract}

\section{Introduction}

Acting as some of the most significant engineering alloys for hightemperature applications, e.g. hot section components in turbine engines, the Nickel-base superalloys are well-performed under cyclic [1] and constant [2] loading condition at elevated temperatures. Nickelbase superalloys are primarily reinforced by a secondary phase, the ordered $\mathrm{L}_{2} \gamma^{\prime}$ intermetallic phase embedded in the continuous disordered FCC austenite $\gamma$ matrix phase [3]. In the $\gamma-\gamma^{\prime}$ Nickel-base superalloys, the volume fraction of $\gamma^{\prime}$ phase could be as high as $50 \%$ for polycrystalline superalloys [4] and single crystal superalloys used for power generation [5] and even up to $70 \%$ for desired creep-resistance in single crystal superalloys for aero engine applications [6]. However, due to the dualphase microstructure configuration, the $\gamma^{\prime}$ strengthened superalloys face the conflicting nature of the strength-ductility paradigm, i.e. the precipitation hardening benefit is based on the cost of ductility. In many respects, the $\gamma-\gamma^{\prime}$ Nickel-base superalloys act as the "classical" two-phase alloy systems.
Recently developed additive manufacturing (AM, known as threedimensional printing as well) techniques, e.g. laser powder-bed-fusion (L-PBF) [7], open up new opportunities for the fabrication of Nickelbase superalloys, with almost no design limitations. Owing to the netshape forming nature, the AM techniques attracts a large amount of interest with regard to component geometrical complexity which permits the use of complicated internal structures for enhanced engineering reliability and energy efficiency in high-temperature applications [8]. Indeed, plenty of research has been conducted on well-known Nickelbase superalloys, such as Inconel 718, Inconel 625 and Hastelloy X, to investigate their printing strategies [9], microstructural evolutions [7], anisotropic mechanical behavior [10] and high-temperature performance [11]. However, the above-mentioned Nickel-base superalloys have limited amount of strengthening phase, e.g. the volume fraction of $\gamma^{\prime \prime}$ strengthening phase in forged Inconel 718 is normally less than $20 \%$ with the grain size smaller than $100 \mathrm{~nm}$ [12], or majorly strengthened by solid solution atoms, e.g. the Inconel 625 [13] and Hastelloy X [14] Nickel-base superalloys.

\footnotetext{
* Corresponding author.

E-mail address: johan.moverare@liu.se (J.J. Moverare).
} 
Importantly, L-PBF can provide an almost $\gamma^{\prime}$-free microstructure in $\gamma-\gamma^{\prime}$ Nickel-base superalloys, compared with its post-processing condition $[15,16]$ or the as-manufactured counterparts by the conventional metallurgical routes $[17,18]$. As reported by Kunze et al. [19], the asbuilt IN738LC superalloy ( $\gamma^{\prime}$ volume fraction up to $43 \%$ after solution treatment [20]) by selective laser melting does not show any $\gamma^{\prime}$ under the observation by scanning electron microscopy. Even in the case of high $\gamma^{\prime}$ fraction Nickel-base alloys, e.g. CM247LC ( $\gamma^{\prime}$ volume fraction up to $65 \%$ [21]), the as-built CM247LC only got 1.5 vol\% nano-sized $\gamma^{\prime}$ secondary phase [22]. Alongside this net-shape or near-net-shape processing benefit from manufacturing prospects, L-PBF provides large thermal gradient and rapid cooling rates (up to hundreds of thousand $\mathrm{K} / \mathrm{s}$ [23]) owing to the localized melting [24]. Several desired microstructural features can be achieved, solidification dendrites are refined [25] and dislocations are favored to form [26].

Inspired by the unique hierarchical microstructure promoted by LPBF and the dual-phase configuration nature of $\gamma^{\prime}$ strengthened Nickelbase superalloys, the microstructural characteristics within the L-PBF material potentially holds the key to overcome the strength and ductility dilemma. We aim to propose a mechanical performance enhancement of the metallic L-PBF built components. In addition, this study will also shed new lights on the strengthening mechanism of the conventional Nickel-base superalloys regarding the heterogenous microstructural aspects, which may be further implemented to design more suitable postprocess treatment after 3D printing of high strength Ni-based superalloys.

\section{Experiment}

The studied Nickel-base superalloy was designated as IN738LC with a modified composition for L-PBF (Ni-16.2Cr-8.5Co-3.5Al-3.5Ti$2.4 \mathrm{~W}-1.8 \mathrm{Mo}-1.7 \mathrm{Ta}-1 \mathrm{Nb}-0.1 \mathrm{C}-0.01 \mathrm{~B}$ ), which is a commercial alloy commonly used for turbine blades and vanes. The IN738LC powder was supplied by Electro Optical Systems Finland Oy. Samples were horizontally built by laser powder-bed-fusion using an EOS M 100 (EOS GmbH) $3 \mathrm{D}$ printing system. The processing parameters of L-PBF were modified to reduce the microcracks as much as possible according to the basis of a design of experiments [27]. The laser power was set to 135-watt with a laser spot size of $40 \mu \mathrm{m}$ and scanning speed of $1150 \mathrm{~mm} / \mathrm{s}$. A powder layer of $20 \mu \mathrm{m}$ thickness and $60 \mu \mathrm{m}$ hatch distance has been used. All the test samples were horizontally built in a stripe pattern. Between each layer, the scanning direction was rotated $67^{\circ}$. The longitudinal direction of the tensile bar was perpendicular to the building direction. For a fair comparison, the tensile properties of the as-built samples, denoted as $\mathrm{AB}$, were compared to post-processing samples from the same batch. The following two post-processing scenarios were implemented: (1) hot isostatic pressing (HIP) at $1000{ }^{\circ} \mathrm{C}$ and standard heat treatment (HT) for IN738LC, denoted as 1000HIP; (2) HIP at $1210{ }^{\circ} \mathrm{C}$ and standard HT, denoted as $1210 \mathrm{HIP}$. The necessary HIP after additive manufacturing effectively heal the microcracks and protects the component from post-processing induced cracking [28]. The internal structure of the three conditions was near-crack-free in the AB sample (crack density: $93 \pm 33 \mu \mathrm{m} / \mathrm{mm}^{2}$ with microcrack length: $33 \pm 10 \mu \mathrm{m}$ ) and crackfree in the HIPed samples with only some remaining isolated porosities (see Fig. S1 in Supplemental material). In order to introduce $\gamma^{\prime}$ phase and grain size differences, we intentionally set the HIP temperature at $1000^{\circ} \mathrm{C}$ and $1210^{\circ} \mathrm{C}$, which are lower and higher, respectively, than the $\gamma^{\prime}$ solvus temperature $\left(\sim 1150{ }^{\circ} \mathrm{C}\right.$ for IN738LC). The IN738LC standard HT combines solution at $1120^{\circ} \mathrm{C}$ for $2 \mathrm{~h}$ and aging at $850{ }^{\circ} \mathrm{C}$ for $24 \mathrm{~h}$.

The tensile testing was performed at a nominal strain rate of $10^{-3} / \mathrm{s}$ using an Instron 5582 testing system at room temperature. Round tensile bars with a gauge length of $25 \mathrm{~mm}$ and a gauge diameter of $5 \mathrm{~mm}$ were prepared by machining from $\Phi 13 \times 80 \mathrm{~mm}$ AM cylinder bars. An extensometer was used to measure strains in the elastic and elastoplastic regime (till 5\%). The detailed pristine microstructures and fracture surfaces were characterized using a Hitachi SU70 field emission scanning electron microscope (FE-SEM) equipped with an Oxford electron backscatter diffraction (EBSD) detector. EBSD data was analyzed using an open-source MATLAB package MTEX [29]. Metallographic etching was performed on 1000HIP and 1210HIP samples to enhance the observation of $\gamma^{\prime}$ phase. The Marble's reagent was used to dissolve $\gamma^{\prime}$ phase by immersion etching for 10-15 s.

Deformation substructures were observed by scanning transmission electron microscopy (STEM) on thin foils prepared from the gauge section of tested tensile bars. Suitable samples were initially ground to $\sim 60 \mu \mathrm{m}$, and then punched into $\Phi 3 \mathrm{~mm}$ circular sheets. The twin-jet electro-polishing was conducted at the polishing temperature of $-25{ }^{\circ} \mathrm{C}$ under $10 \%$ perchloric acid and $90 \%$ ethanol electrolyte solution. The STEM investigation was performed on a FEI Tecnai G2 microscope operated at $200 \mathrm{kV}$. Images where taken using an annular detector operated at various camera lengths, high angle annular dark field images with a camera length of $140 \mathrm{~mm}$, dark field $350 \mathrm{~mm}$ and bright field $2100 \mathrm{~mm}$.

The nanoindentation hardness tests were carried out at room temperature on the UMIS Nanoindentation system with a Berkovich tip. The surface of nanoindentation test samples were carefully polished using Struers OP-U colloidal silica suspension to reduce the effect of surface hardening layer. The nanohardness test was performed on the loadcontrolled mode. The loading rate was $1 \mathrm{mN} / \mathrm{s}$ and the peak load was $20 \mathrm{mN}$. The nanoindentation interval spacing was $10 \mu \mathrm{m}$ for $\mathrm{AB}$ and 1000 HIP samples which have fine grain structure but $20 \mu \mathrm{m}$ for coarse grain structured 1210HIP sample.

\section{Results}

\subsection{Microstructure of $L-P B F I N 738 L C$}

The pristine microstructures of the undeformed samples under the three different post-treatment conditions are illustrated in Fig. 1. The grain microstructure of the $A B$ sample is columnar shaped (Fig. 1(a)), in which the fine grains are generally oriented along the building direction. In the post-thermal treated samples, the grain structures are distinctly different. Owing to the applied HIP temperature, the 1000HIP sample (Fig. 1(b)) has similar grain structures and grain morphology as the $\mathrm{AB}$ sample ((Fig. 1(a)), while the 1210HIP sample has a totally different grain configuration. Strong grain growth during super-solvus HIP treatment resulted in a relatively faceted grain morphology (Fig. 1(c)). The average grain size of the as-built sample is $44 \mu \mathrm{m}$, and after HIP at $1000^{\circ} \mathrm{C}$ and $\mathrm{HT}$, the average grain size slightly grows to $50 \mu \mathrm{m}$. After HIP at $1210{ }^{\circ} \mathrm{C}$ and $\mathrm{HT}$, the average grain size obviously grows to $154 \mu \mathrm{m}$. Here, the grain size is derived from the square root of grain area which surrounded by high angle grain boundaries (GBs) with misorientation higher than $10^{\circ}$, from EBSD measurements.

Beyond the grain structures, the high magnification SEM backscattered electron image shows that within the grains of the $\mathrm{AB}$ sample (Fig. 1(d)), the interior microstructure can be identified as a sub-micron sized cellular structure with a measured average size $d_{c}=423 \mathrm{~nm}$. These cellular structures share the comparable size with the primary dendrite arm spacing $\lambda_{1}$, which is negatively correlated with the cooling rate, $\dot{T}$, as $\lambda_{1} \propto \dot{T}^{-0.3}$ [30]. Due to the rapid solidification condition of L-PBF, i.e. up to $10^{6} \mathrm{~K} / \mathrm{s}$ [31], these cellular structures are restricted to submicron size. Meanwhile, these cellular structures induced by L-PBF can be commonly found in different alloy systems in the as-built state. For example, in this study IN738LC has similar cellular size to a selective laser melted CoCrFeNiMn high entropy alloy [26] and 316 L stainless steel [32]. Messé et al. [33] reported that the cellular boundaries are composed by high density of dislocations as a feature of the L-PBF process in as-built IN738LC superalloys. Similarly, Qiu et al. [34] reported the cellular band with large amount of dislocation in L-PBF IN738LC.

The $\gamma-\gamma^{\prime}$ dual phase microstructural configuration of 1000HIP and 1210HIP are shown in Fig. 1(e) and Fig. 1(f) by SEM secondary electron imaging, respectively. Both 1000HIP and 1210HIP have $\gamma^{\prime}$ phase of divergent sizes and morphologies. Obviously, the characteristics 

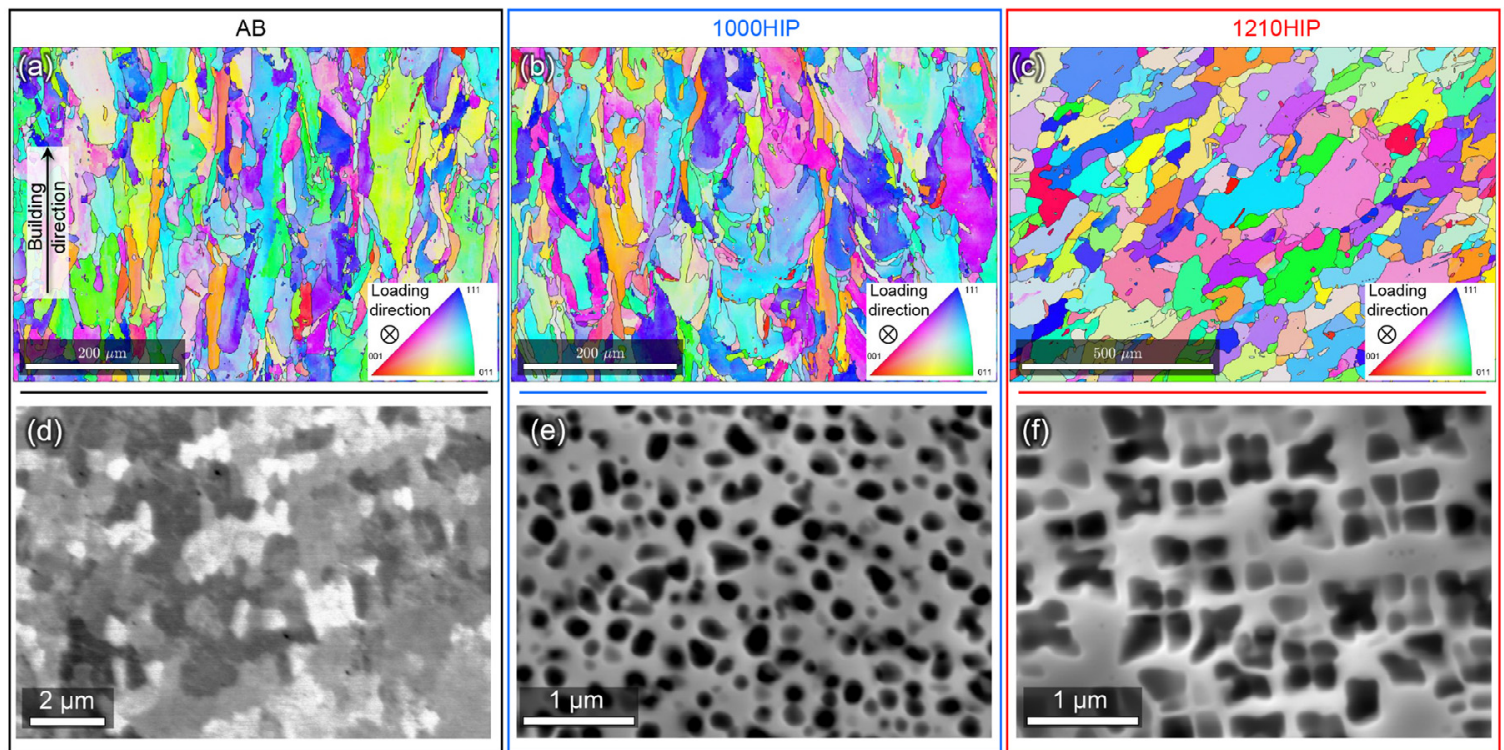

Fig. 1. Microstructural images of pristine microstructures of the undeformed samples in this study, EBSD-IPF coloring maps (reference axis parallel to loading direction) and their corresponding pole figures of (a) AB sample, (b) 1000HIP sample, (c) 1210HIP sample, (d) SEM backscattered electron (BSE) image of AB sample showing the sub-micron size cellular structure, (e) SEM secondary electron (SE) image of 1000HIP sample showing the spherical $\gamma^{\prime}$ precipitates and (f) SE image of 1210HIP sample showing the cuboidal $\gamma^{\prime}$ precipitates.

of $\gamma^{\prime}$ phase are easily distinguished, as the sub-solvus HIP treatment (1000HIP) results in moderate-size $\gamma^{\prime}$ but the super-solvus HIP treatment (1210HIP) renders coarser $\gamma^{\prime}$. By image analysis, it is observed that the 1000HIP sample is composed of $\gamma^{\prime}$ phase with a spherical shape $\left(d_{\gamma^{\prime}}=180 \mathrm{~nm}\right.$ and an estimation volume fraction of $\left.f_{\gamma^{\prime}}=35 \%\right)$, as in Fig. 1(e). In contrast, under the super-solvus HIP temperature, the cuboidal $\gamma^{\prime}\left(d_{\gamma^{\prime}}=400 \mathrm{~nm}\right.$ and volume fraction of $\left.f_{\gamma^{\prime}}=45 \%\right)$ are formed in the 1210HIP sample, as shown in Fig. 1(f). Besides the $\gamma^{\prime}$ phases, carbides are observed in post-thermal treated samples. In 1000HIP sample, Cr- and Mo- enriched $\mathrm{M}_{23} \mathrm{C}_{6}$ carbides are occasionally found at grain boundaries (Fig. S2 in Supplemental information), while Ti-, Nb- and Ta- enriched MC carbides were observed at both grain boundaries and grain interior in 1210HIP sample (Fig. S3).

In addition to the coarse grain structure in the 1210HIP sample, the crystallographic characteristics of the cuboidal $\gamma^{\prime}$ are further illustrated by EBSD in Fig. 2. Here, two sub-areas with the orientation close to [001] (Fig. 2(b)) and [011] (Fig. 2(c)) are selected from the inverse pole figure (IPF) coloring map. The morphology of these coarse $\gamma^{\prime}$ phases are shown in Fig. 2(d and e) with the corresponding pole figures of the sub-areas. It can be seen that the edge of the cuboidal $\gamma^{\prime}$ are aligned with the trace of $\{100\}$ crystallographic planes, leading to the $\{111\}$ crystallographic plane traces to appear in the diagonal direction of the $\gamma^{\prime}$ precipitates. Potentially affecting dislocations movement with respect to the specified $\gamma^{\prime}$ phase morphology along specific cryptographical planes, which will be further discussed in Section 4.1.

\subsection{Uniaxial tensile response at room temperature}

The mechanical response of the L-PBF manufactured IN738LC samples are compared in Fig. 3, depicting the strengthening influence of the different microstructures. The mechanical properties including $0.2 \%$ offset yield strength (YS), ultimate tensile strength (UTS) and elongation (EL) -to-fracture are summarized in Table 1 . All the tested engineering stress-strain curves are available in Fig. S4 in the Supplementary information. As shown in the engineering stress-strain curves of the representative specimens from different treatment scenarios (Fig. 3(a)), a distinctive difference in mechanical behavior can be observed. Firstly, the 1000HIP sample exhibits the highest yield strength, up to approxi-
Table 1

The mechanical properties of $\mathrm{AB}, 1000 \mathrm{HIP}$ and $1210 \mathrm{HIP}$ L-PBF IN738LC superalloy.

\begin{tabular}{llll}
\hline Alloys & $0.2 \%$ YS (MPa) & UTS (MPa) & EL $(\%)$ \\
\hline $\mathrm{AB}$ & 1075.5 & 1360.5 & 18.9 \\
& 1093.0 & 1367.8 & 18.9 \\
\multirow{2}{*}{ 000HIP } & 1339.1 & 1472.1 & 4.5 \\
& 1296.5 & 1449.5 & 4.0 \\
& 1285.2 & 1462.5 & 4.6 \\
& 1300.6 & 1383.0 & 3.0 \\
& 1309.7 & 1484.6 & 4.9 \\
$1210 \mathrm{HIP}$ & 1315.4 & 1496.1 & 5.1 \\
& 887.5 & 1270.0 & 10.6 \\
& 882.0 & 1361.5 & 14.9 \\
& 919.8 & 1398.3 & 16.2 \\
& 915.4 & 1375.7 & 14.5 \\
\hline
\end{tabular}

mate $1300 \mathrm{MPa}$, but limited ductility with a tensile elongation of $\sim 4.5 \%$. It is also clearly shown that the post-processing conditions play a significant role for the tensile properties, the higher HIP temperature at $1210^{\circ} \mathrm{C}$ results in the lowest yield strength $(\sim 882 \mathrm{MPa})$ but better elongation ( $\sim 14.9 \%)$ for the 1210HIP sample. More strikingly, the AB sample displays a good combination of both yield strength ( $1093 \mathrm{MPa})$ and ductility $(\sim 18.9 \%)$.

To demonstrate the synergic strength-ductility improvement of the $\mathrm{AB}$ sample, the test results in this study and from literature (open triangle and square mark) are put together in Fig. 3(b) for comparison [35-37], where other traditional $\gamma^{\prime}$ hardened cast Nickel-base superalloys are included as well (open diamond mark). Compared with the $\gamma-\gamma^{\prime}$ two-phase structure of Nickel-base superalloys, it can be seen that the $\mathrm{AB}$ sample has relatively high yield strength and at the same time exhibits extremely good ductility, suggesting that the effective strengthening was achieved without compromising the ability for plastic mediation. In contrast, owing to the similar two-phase microstructural configuration, the 1000HIP and 1210HIP $\gamma-\gamma^{\prime}$ superalloys are trapped in the strength-ductility dilemma (left-lower corner in Fig. 3(b)). 

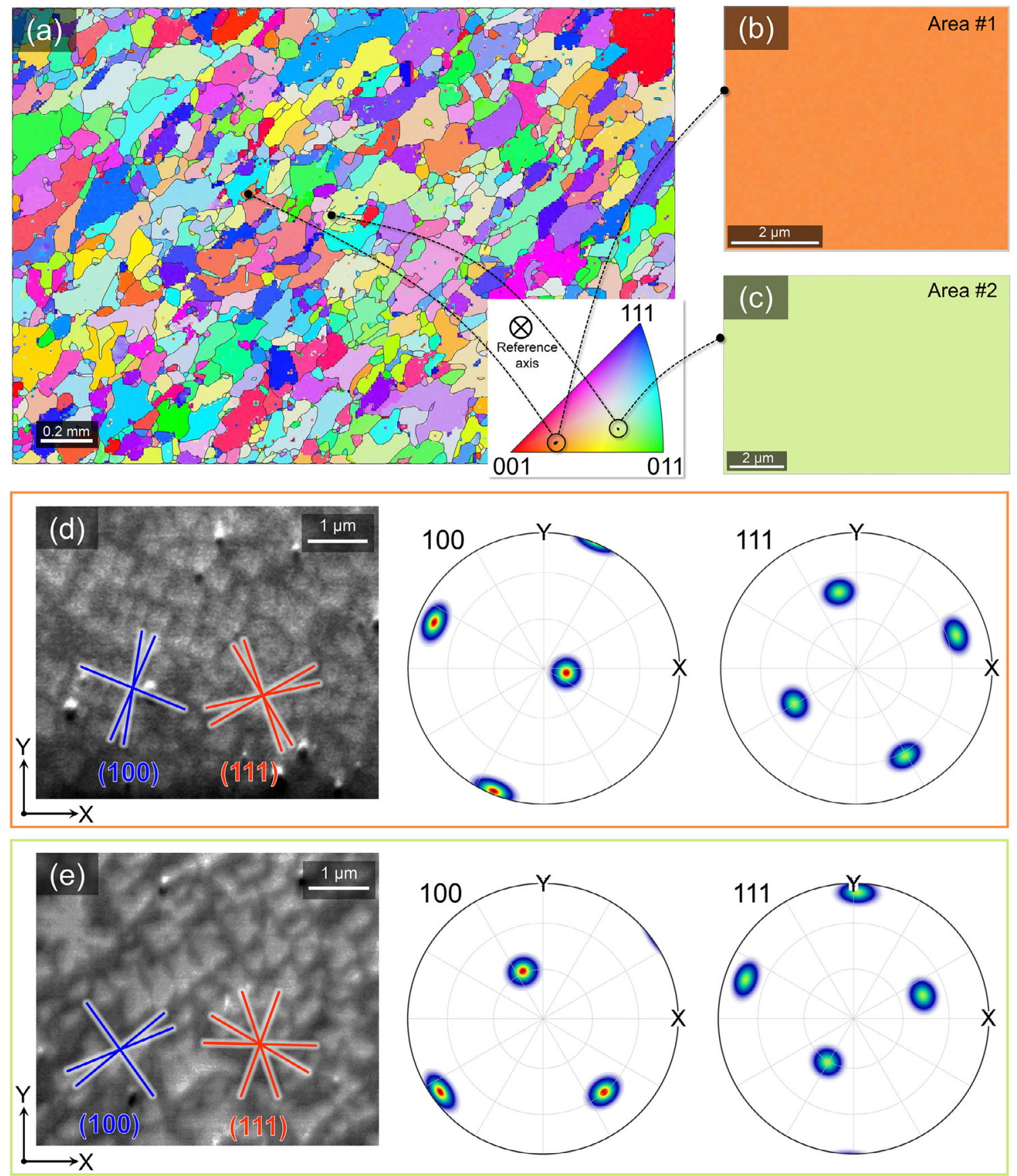

Fig. 2. (a) EBSD IPF coloring map of $1210 \mathrm{HIP}$ sample from observation plane perpendicular to the loading direction, (b) selected sub-area \#1 with orientation close to [001], (c) selected sub-area \#2 with orientation close to [011], (d) the $\gamma^{\prime}$ phase morphology in sub-area \#1 with its corresponding \{100\} and \{111\} pole figure, (e) the $\gamma^{\prime}$ phase morphology in sub-area \#2 with its corresponding $\{100\}$ and $\{111\}$ pole figures.

\subsection{Fractography observations}

In this study, fractography was used to identify the differences between the fracture modes for the different microstructures. Post-mortem fractography of the three samples were carefully examined and presented in Fig. 4(a)-(c) for AB, 1000HIP, and 1210HIP samples, respectively. Crystallographic cracks dominate the fracture surface of the $A B$ sample (Fig. 4(a1)) caused by the failure response to its single-phase structure. The evidence of intergranular cracks is shown in the 1000HIP sample (Fig. 4(b1)), and 1210HIP sample (Fig. 4(c1)). The size and morphology of the intergranular cracks are in good agreement with the corresponding pristine grain structure in Fig. 1. Non-fatal intergranular cracks can be observed, as the white arrows show in Fig. 4(b1) and (c1), resulting from the decohesion of grain boundaries. These intergranular cracks for the $1000 \mathrm{HIP}$ and 1210HIP samples are consistent with the room temperature tensile fracture of cast IN738LC superalloy with fine $\gamma^{\prime}(\sim 70 \mathrm{~nm})$ and coarse $\gamma^{\prime}(\sim 700 \mathrm{~nm})$ microstructures [37].

Interestingly, a ductile fracture mode through dimple formation by voids nucleation and growth could be found in all samples. As shown in Fig. 4(a2)-(c2), all the tested samples have different scales of ductile dimples, even though the 1000HIP sample which has limited tensile elongation. The sizes of the dimples are well matched with the corresponding microstructure within the grain interior (cellular structure $\sim 423 \mathrm{~nm}$ in $\mathrm{AB}$ and $\gamma^{\prime}$ secondary phase $\sim 180 \mathrm{~nm}$ and $\sim 400 \mathrm{~nm}$ in 

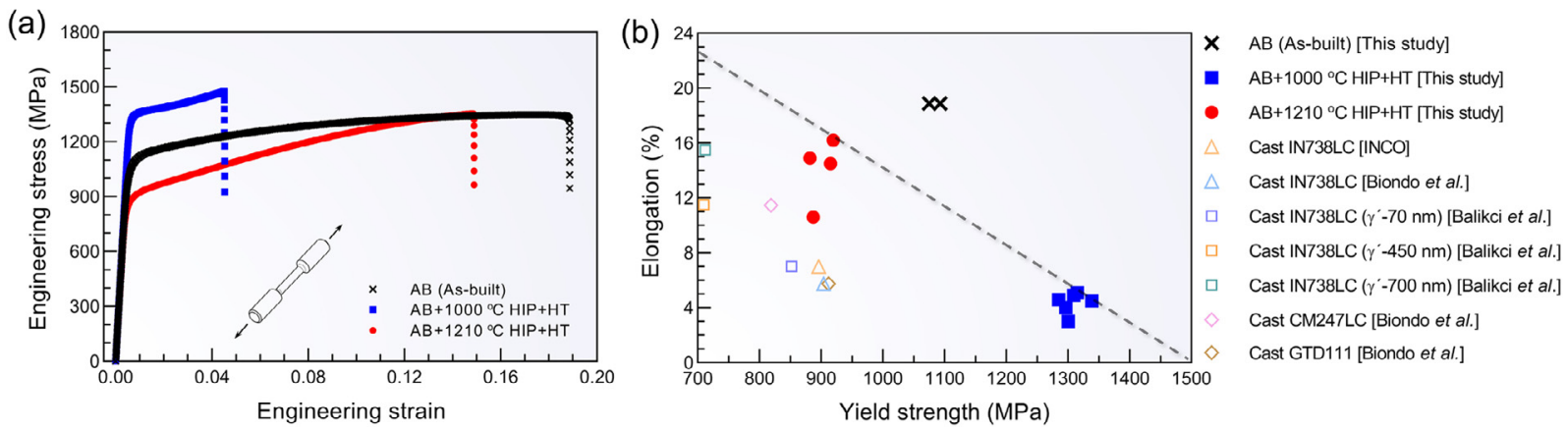

Fig. 3. (a) Representative engineering stress-strain curves of the $\mathrm{AB}, 1000 \mathrm{HIP}$ and $1210 \mathrm{HIP}$ specimens. (b) Yield strength versus the tensile elongation of the $\mathrm{AB}$, 1000HIP and 1210HIP specimens compared with those of other cast IN738LC, CM247LC and GTD111 Nickel-base superalloys.

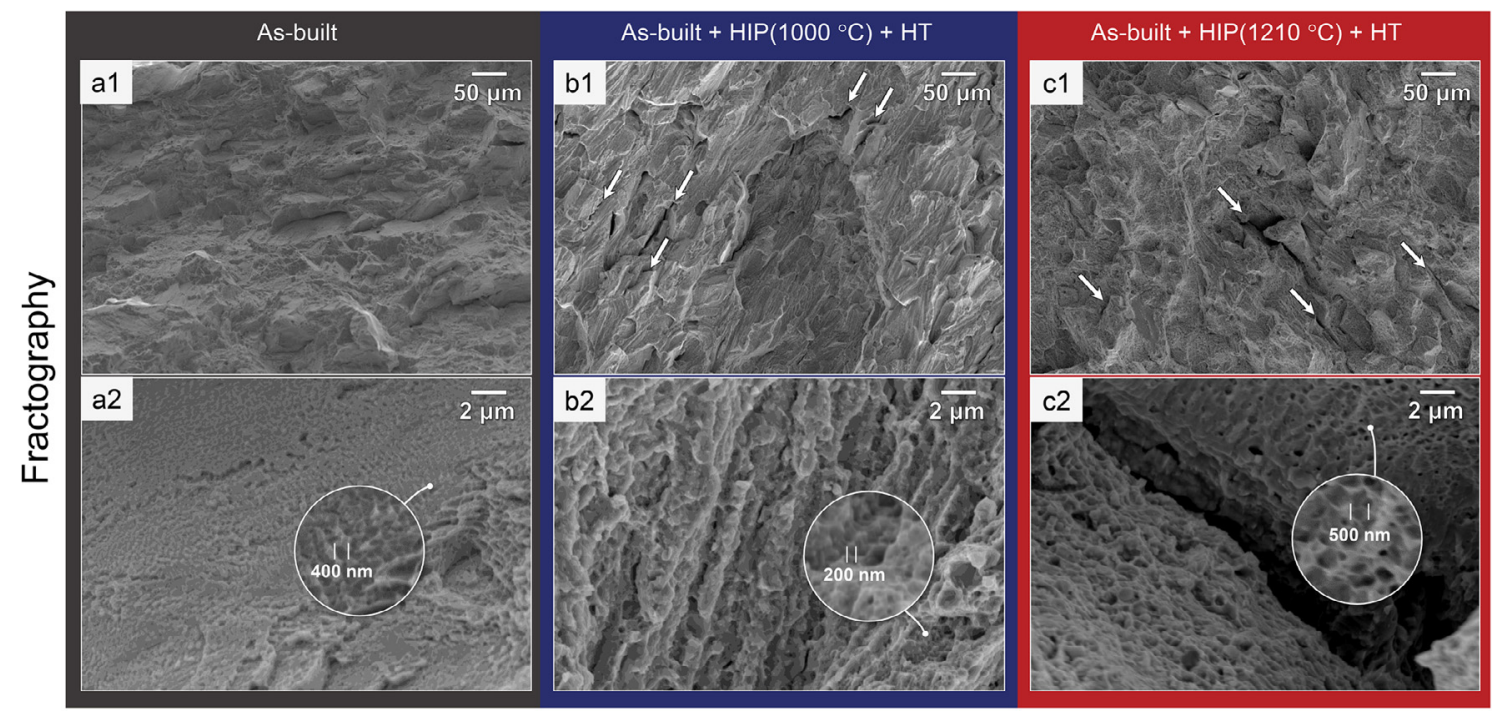

Fig. 4. Typical fractography of the room temperature tensioned samples from SEM secondary electron images, (a1), (b1), (c1) overall view of the fracture surface of $\mathrm{AB}, 1000 \mathrm{HIP}$, and 1210HIP, respectively, (a2), (b2), and (c2) high-magnification micrographs show the dimple ruptures of AB, 1000HIP, and 1210HIP, respectively.

$1000 \mathrm{HIP}$ and 1210HIP, respectively). For the post-thermal treated samples, the dimples are postulated to be formed from the debonding of the $\gamma^{\prime}$ precipitates and $\gamma$ matrix interface. The primary strengtheners for $\mathrm{AB}$, $1000 \mathrm{HIP}$, and $1210 \mathrm{HIP}$ samples can be deduced as the cellular structure, the fine $\gamma^{\prime}$ phase, and coarse $\gamma^{\prime}$ phase, respectively. As reported from Balikci et al. [37], the size of dimples is equivalent to the size of $\gamma^{\prime}$.

The cross-sectional fractography of 1000HIP and 1210HIP samples can be found in Fig. S5 and Fig. S6, respectively. The intergranular cracking of these two samples could be attributed to the interaction between GBs and GB carbides. In Nickel-base superalloys, the GB carbides play an important role in inhibiting the GB sliding during hightemperature deformation. The cause of uncommon GB sliding at room temperature is discussed in Section 4.3 in detail.

\section{Discussion}

\subsection{On the strengthening mechanisms}

In this section, the strengthening mechanisms of all the three samples will be discussed in detail by combination of microstructural evidence and mathematic interpretation.

Firstly, by considering the contribution of grain boundaries to the yield strength, the well-known Hall-Petch relation is used and the increment of yield strength is quantified as:

$\Delta \sigma_{G B}=\frac{k_{y}}{\sqrt{d_{m}}}$
Where $k_{y}$ is the Hall-Petch coefficient, which is $710 \mathrm{MPa} / \mu \mathrm{m}^{1 / 2}$ for general Nickel-base superalloys [38] and $d_{m}$ is the average grain size. The calculated $\Delta \sigma_{G B}$ is $107 \mathrm{MPa}, 100 \mathrm{MPa}$, and $57 \mathrm{MPa}$ for the $\mathrm{AB}$, $1000 \mathrm{HIP}$, and $1210 \mathrm{HIP}$ specimens, respectively.

\subsubsection{As-built sample}

To further unravel the deformation micro-mechanism of the three samples, detailed scanning transmission electron microscopy (STEM) investigations were carried out. Fig. 5 shows the deformation substructures of the $A B$ sample from both top view and side view of cellular structures. It is clearly shown in Fig. 5(a1) and (b1) that the cellular walls are composed of highly tangled dislocations. Owing to the observed different features of the cellular bulk and the cellular wall with a regular distribution pattern, the cellular structure is best described as a "composite" deformation substructure [39]. Cellular wall thickness, $h$, is measured to approximate $30 \mathrm{~nm}$ in the "clean" cellular wall region, as shown in the inset of Fig. 5(b1), with limited deformation activities avoiding the contrast influence from dislocation tangles. Comparing with the cellular size $d_{c}, h$ is far less than $d_{c}$. Therefore, the volume fraction $f_{w}$ of cellular wall can be calculated as [39]:

$f_{w} \approx \frac{\kappa h}{d_{c}}$

Where $f_{w}, h$, and $d_{c}$ are defined previously, and $\kappa$ is a geometric constant set as 3 for a regular cellular structure. This results in a cellular volume fraction around $21 \%$. 

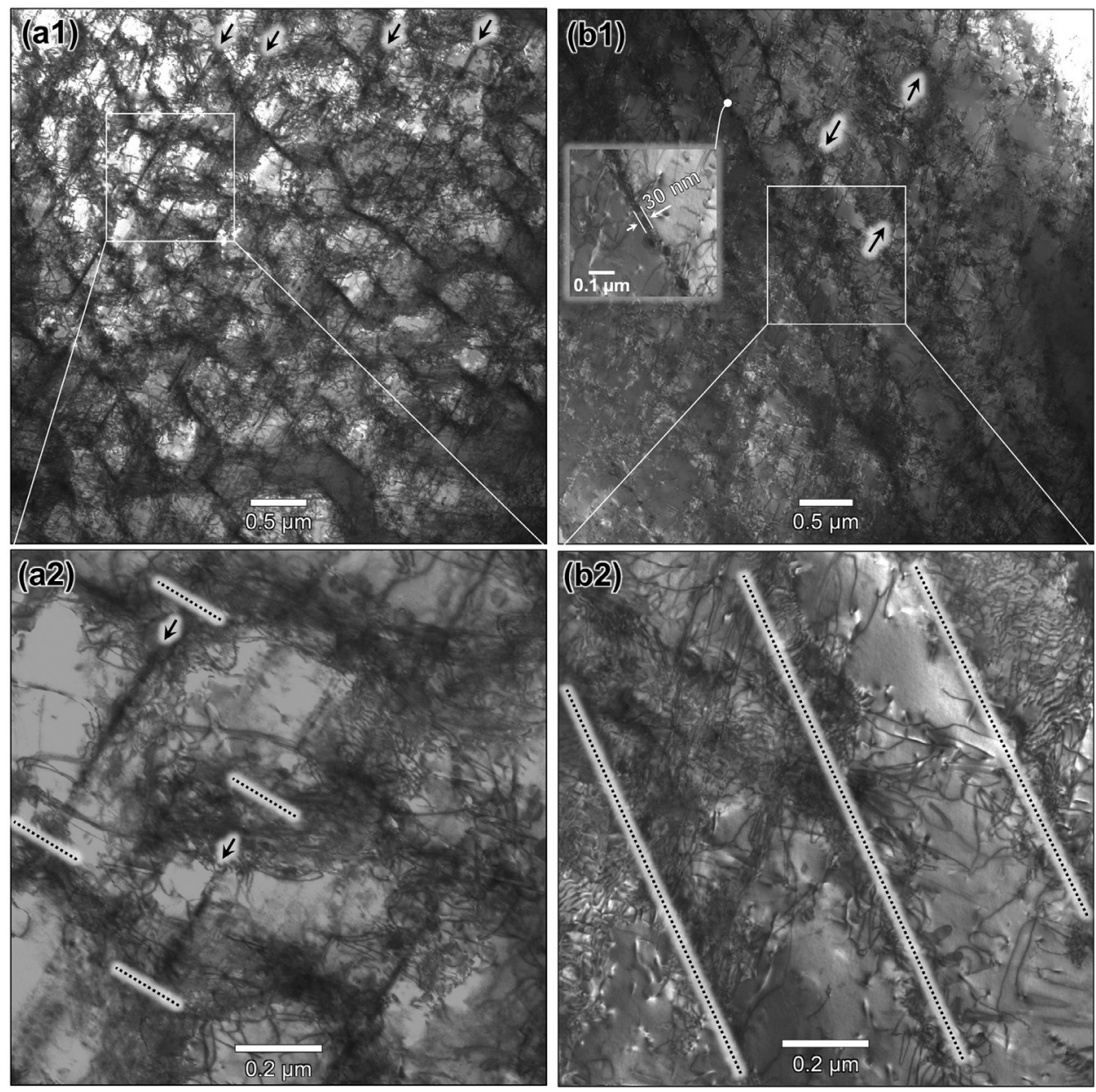

Fig. 5. Bright field STEM micrographs of the deformed $\mathrm{AB}$ specimen, demonstrating the major deformation mechanism and cellular walls interaction, (a) top view and (b) side view of cellular structure.
Owing to its single-phase structure, the glide of dislocations is the main operative deformation mode. As indicated by the black arrows in Fig. 5(a1) and (a2), slip bands are parallelly arrayed. By further increasing the imaging magnification, the interaction between slip bands and dislocation cellular walls is shown in Fig. 5(a2). As shown in the section between the paired dashed lines, the slip bands are mainly restricted within the dislocation cell interior. Thus, the cell walls with an extremely high density of dislocations effectively block the motion of gliding dislocations.

More dislocation substructures are illustrated in Fig. 6 to show the planar slip character of the deformed $\mathrm{AB}$ samples. The nature of the dislocation substructure is characterized by the planar slip bands, as shown as classical planar slip band fingerprints in Fig. 6(b). During the deformation process, the carpet-like dislocation substructure formed due to the activation of double or multiple slip systems. The planar slip planes follow the traces of the $\{111\}$ planes, which are shown as the yellow cross in Fig. 6(a). It is commonly observed in low stacking fault energy materials that after the onset of extensive planar dislocation bands in the stage I work hardening state, secondary slip system could be activated to keep a certain amount of work hardening. This double or even multiple planar slip lead to the formation of the "carpet-like" dislocation substructure configuration [40], as shown in Fig. 6(a1) and (a2).

It is believed that the nature of rapid cooling $\left(\sim 10^{6} \mathrm{~K} / \mathrm{s}\right)$ to ambient temperature involved in the L-PBF process leaves a large amount of dislocations behind. Due to the dislocation heterogeneity, the AB samples are hardened. Other processes commonly involving several steps of cold working and tempering also introduce high dislocation density [41], however the L-PBF process can provide this cellular character in a net-shape or near-net-shape manufactured condition. As analyzed from the mechanical performance and deformation mechanisms, the disloca- tion cellular strengthening has a big impact on the $\mathrm{AB}$ sample. It is well accepted that the strengthening effect of dislocation substructures can be estimated by the Taylor relation using the corresponding dislocation density $[42,43]$.

For strengthening by a huge amount of heterogeneously distributed dislocations as in the $\mathrm{AB}$ sample shown in Figs. 5 and 6, it is inaccurate to measure the overall dislocation density across the cell walls and cell interiors. In addition, due to the large amount of dislocations squeezed in the cellular wall region, it is almost impossible to directly measure the dislocation density in these areas. Several relationships between the cellular size and dislocation density have been proposed. For example, as proposed by Holt [44], the cellular size is comparable to the wavelength of dislocation density modulation, caused by the energetic unstable significance of the uniformly distributed distribution to cluster. It is commonly expressed as [45]:

$\rho=\frac{c}{d_{c}^{2}}$

Where $\rho$ is dislocation density, $d_{c}$ is the average cellular size as $423 \mathrm{~nm}$ in this study, and $c$ is a constant for a given materials. The generally used value for $c$ is 1 , as reported in [26,46]. Based on this assumption, the resulted $\rho$ is determined as $5.6 \times 10^{12} / \mathrm{m}^{2}$, which is $1-2$ order less than the reasonable value for L-PBF alloys such as selective laser melted high entropy alloy [47].

Therefore, instead we determined the dislocation density within the cells using the intersection measurement method [48] from TEM images to be $7.14 \times 10^{14} / \mathrm{m}^{2}$ (Std. Dev.: $0.58 \times 10^{14} / \mathrm{m}^{2}$ ). By inserting the measured dislocation density result and cellular size value back into Eq. (3), it gives the material dependent constant $c=128$. This fitted value is consistent with other empirical results as $c$ has been reported to be in the 

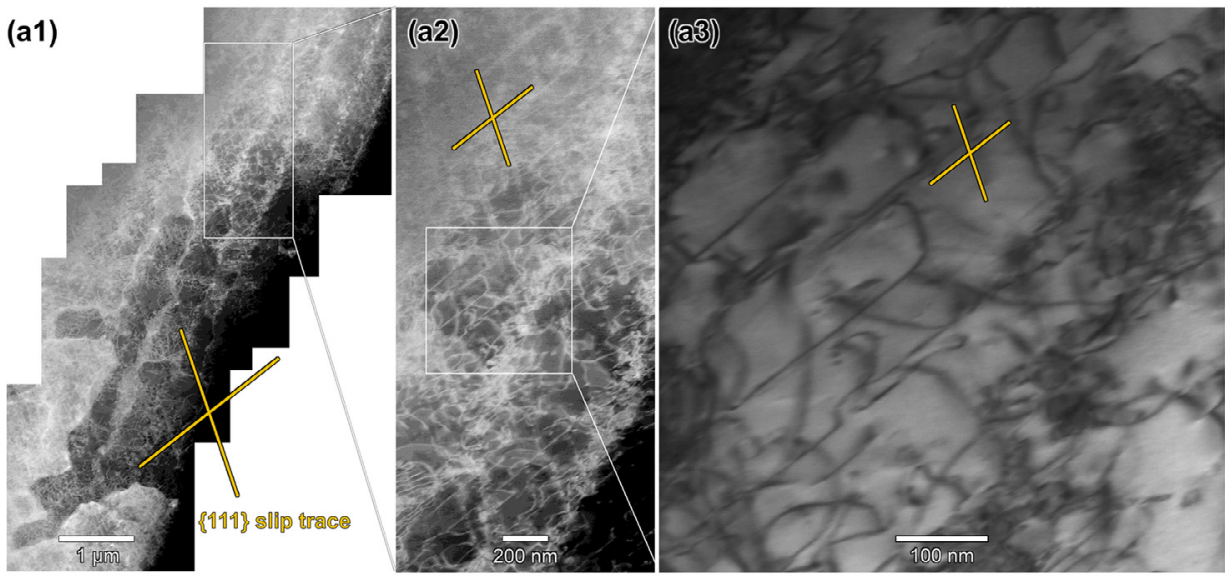

(b1)
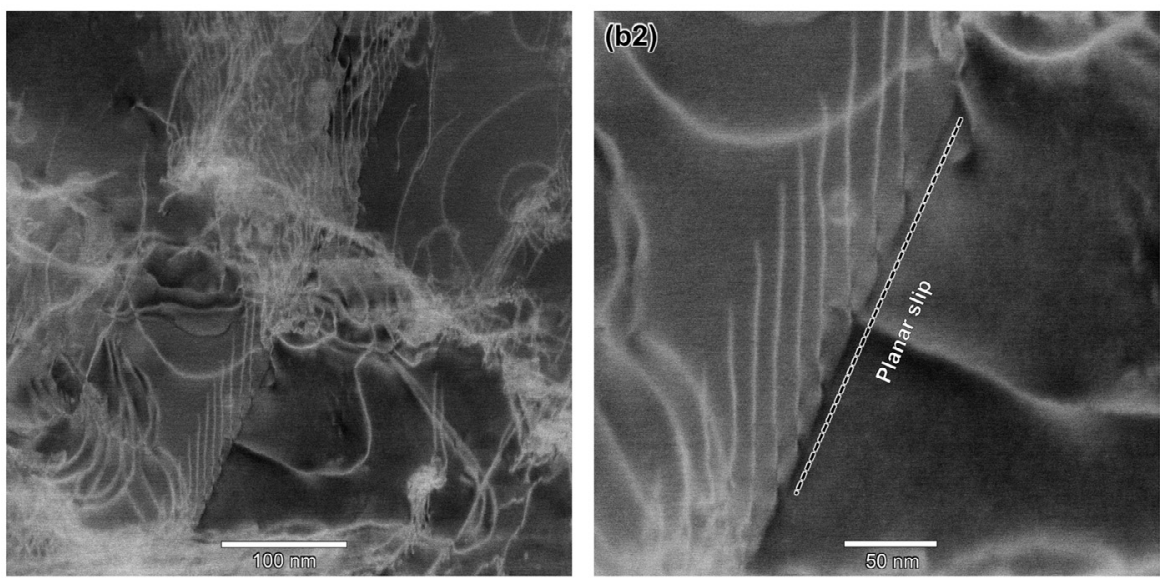

Fig. 6. Deformation substructure of the AB specimen, (a) double slip activities between cell walls, (b) detail feature of planar slip. ((a1-2) and (b1-2) are taken from dark field STEM imaging and (a3) from bright field STEM imaging). range of 80-170 [49]. When replacing the bulk dislocation density with the cell interior dislocation density, the dislocation walls are assumed undeformed and no hardening effect should be added. Then the Taylor's equation is rewritten as:

$\Delta \sigma_{\text {Dis. }}=f_{c} \alpha \bar{M} G b \sqrt{\rho}$

Here $f_{c}$ is the cell fraction (79\%), $\alpha$ is a constant. The average $\bar{M}$ value is given to be $3.19,3.09$, and 3.10 for $\mathrm{AB}, 1000 \mathrm{HIP}$, and 1210HIP, respectively based on EBSD measurement. Owing to the nature of dislocation heterogeneity in this study, using an $\alpha$ value for homogeneously distributed dislocations $\alpha_{\text {Hom. }}(0.3)$ will result in higher strengthening values. Herein, we use a modified $\alpha$ value for cell-containing dislocation structures as proposed in [49]:

$\alpha=2 \alpha_{\text {Hom. }} \sqrt{f_{c} f_{w}}$

Where $f_{w}$ is the cell wall fraction (21\%) and $f_{c}$ is the cell fraction (79\%). The calculated contribution $\Delta \sigma_{D i s}$ is then $372 \mathrm{MPa}$, which ensures the AB sample's high-strength performance in spite of its single-phase structure.

\subsection{2. $1000 \mathrm{HIP}$ and 1210HIP samples}

In the post-thermal treated samples, $1000 \mathrm{HIP}$ and $1210 \mathrm{HIP}$, the yield strength is greatly enhanced due to the precipitation of spherical $\gamma^{\prime}$ precipitates in 1000HIP sample but reduced while the coarse $\gamma^{\prime}$ phase appear in 1210HIP sample. Distinctly, after post-processing, secondary $\gamma^{\prime}$ precipitated, as shown in Fig. 7(a) and (b). The $\gamma^{\prime}$ phase has a $\mathrm{L} 1_{2}$ crystal structure, with the stoichiometry $\mathrm{Ni}_{3} \mathrm{Al}$, which is near-coherent with the FCC $\gamma$ matrix. This $\mathrm{L}_{2} \gamma^{\prime}$ phase acts as the effective strengthening source for the commercial Nickel-base superalloys and other austenite-based alloys [50]. Fig. 7(a1) shows the representative deformation substructure of the 1000HIP sample. Two sorts of dislocation activities are observed:
(1) dislocation lines occupied the continuous $\gamma$ channel with the length up to micron-scale (as shown in parallel dotted-lines in Fig. 7(a1)); (2) other dislocations loop around the $\gamma^{\prime}$ phase (e.g. $\gamma^{\prime}$ within blue circled area in Fig. 7(a1)). It is clearly demonstrated that the soft domain $(\gamma$ matrix) provides the dislocation accommodation area, which is fully squeezed with dislocations (Fig. 7(a2)). For the coarse $\gamma^{\prime}$ in the 1210HIP sample (Fig. 7(b1)), the strengthening mechanism is similar: dislocations loop around $\gamma^{\prime}$ (shown as the red ellipses). The cuboidal $\gamma^{\prime}$ phase has specific crystallographic planes as the phase outer edges are aligned with the $\{100\}$ crystal planes of the FCC matrix, as determined by EBSD in Fig. 2. The red ellipses indicated in Fig. 7(b) match the trace of $\{111\}$ slip systems in the corresponding matrix. However, the coarse $\gamma^{\prime}$ has less efficiency in strengthening, which results in the more undeformed $\gamma$ matrix (Fig. 7(b2)), where the 1210HIP sample has less dense dislocations than the 1000HIP counterpart in Fig. 7(a2). As a consequence, the $1210 \mathrm{HIP}$ sample can accommodate the deformation easier and a better tensile elongation is achieved compared to the 1000HIP sample.

Confirmed by the deformation substructure analysis in the two postprocess treated samples (Fig. 7(a) and (b)), the dislocations interact with $\gamma^{\prime}$ in the manner of Orowan looping. Then, the strength given by the $\gamma^{\prime}$ phase can be written as Orowan stress $\tau_{O r}$ as [51]:

$\Delta \sigma_{\gamma^{\prime}}=\bar{M} \tau_{O r}=\bar{M} \frac{G b}{L_{s}}$

Where $L_{s}$ is the spacing between the precipitates. For spherical particles, $L_{s}$ is determined by the $\gamma^{\prime}$ volume fraction, $f_{\gamma^{\prime}}$, and the size of $\gamma^{\prime}, d_{\gamma^{\prime}}$ as [52]:

$L_{s}=\sqrt{\frac{8}{3 \pi f_{\gamma^{\prime}}}} d_{\gamma^{\prime}}-d_{\gamma^{\prime}}$ 


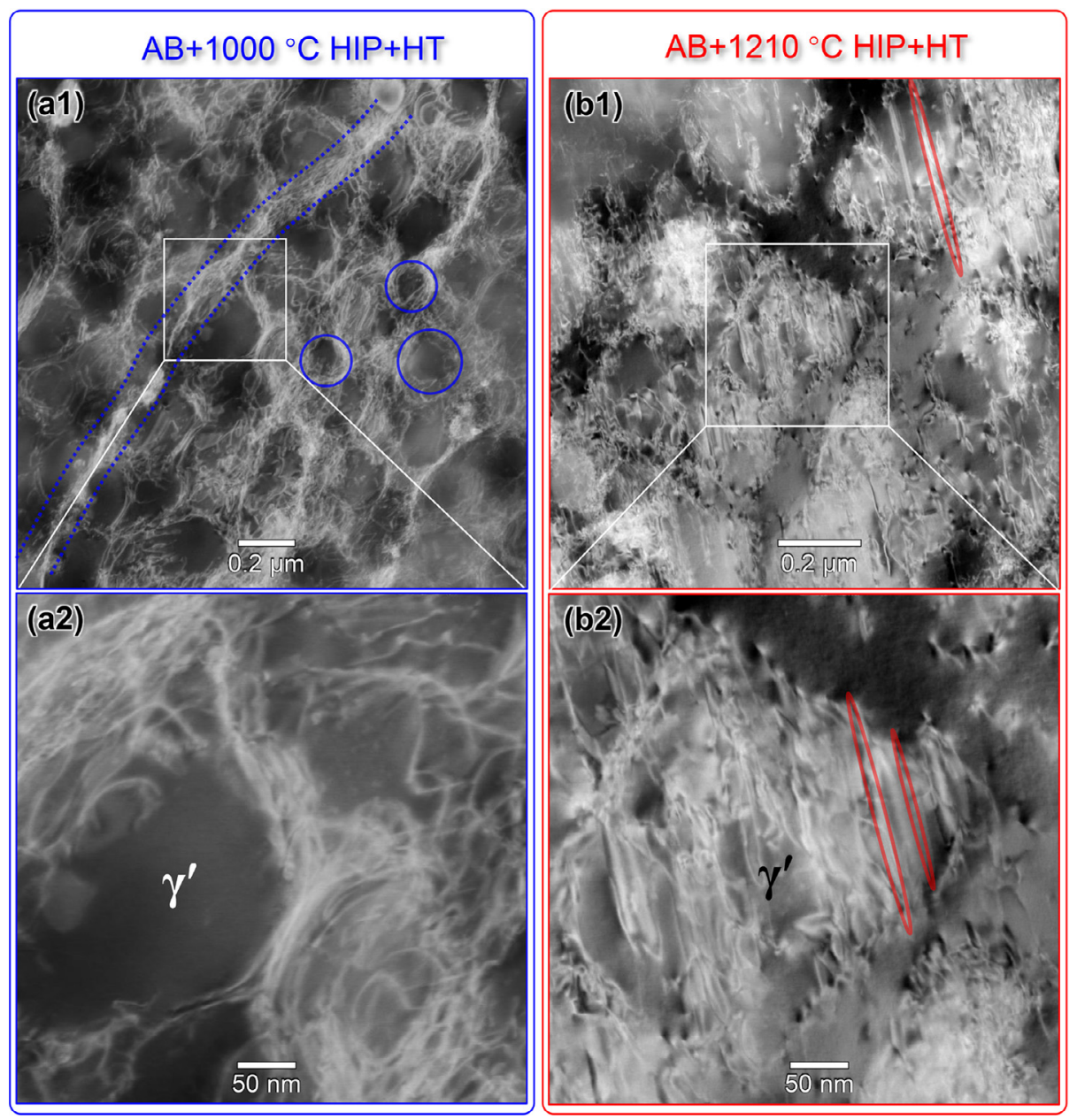

Fig. 7. Dark field STEM micrographs of typical deformation substructure of post-thermal treated specimens, (a) 1000HIP, (b) 1210HIP.

Here, $L_{s}$ is calculated to be $100 \mathrm{~nm}$ and $149 \mathrm{~nm}$ for $1000 \mathrm{HIP}$ and 1210 HIP, respectively. The contribution of $\gamma^{\prime}$ to strength is then calculated to be $696 \mathrm{MPa}$ and $469 \mathrm{MPa}$ for 1000HIP and 1210HIP sample, respectively. It should be noted that the $L_{s}$ value in Eq. (6) is modified for spherical shaped particles, but the 1210HIP sample has cuboidal shaped $\gamma^{\prime}$. Then we calculated the $\Delta \sigma_{\gamma^{\prime}}$ for this sample directly using the $\gamma$ channel spacing $L$ as [38]:

$\Delta \sigma_{\gamma^{\prime}}=\frac{3}{2} \bar{M} \frac{G b}{\mathrm{~L}}$

Owing to the orientation dependence of the $\gamma^{\prime}$ in 1210HIP sample, the $\gamma$ channel spacing $L$ is measured through the diagonal intersects in the $\gamma$ phase, as measured to be $225 \mathrm{~nm}$ on average. It gives the close value of $467 \mathrm{MPa}$ as compared to $469 \mathrm{MPa}$ calculated from Eqs. (6) to (7). By combining the micrograph analysis and mathematical calculations, it is found that the ordered precipitates effectively harden the material by hindering the dislocation movements. A high density of dislocations was generated as a response to the precipitate blocking effect. In addition, in the regime of the Orowan loop mechanism, the strengthening effect is highly dependent on the precipitate spacing with respect to the precipitate size.

Therefore, based on the discussion above, we aim to quantify the yield strength of the three different samples. For the $\gamma^{\prime}$ strengthened and highly alloyed polycrystalline Nickel-base superalloys, the increase in yield strength $\Delta \sigma_{y}$ can be expressed using several separate strengthening factors, on the assumptions that these mechanisms operate independently, the addition law can be used [52]:

$\Delta \sigma_{y}=\Delta \sigma_{S S}+\Delta \sigma_{G B}+\Delta \sigma_{\gamma^{\prime}}+\Delta \sigma_{D i s}$
Where $\Delta \sigma_{S S}$ is from solid-solution strengthening, $\Delta \sigma_{G B}$ is the strength contributed by the grain boundaries, $\Delta \sigma_{\gamma^{\prime}}$ is the strength contributed by the $\gamma^{\prime}$ precipitates, which is highly dependent on the size of $\gamma^{\prime}$, and $\Delta \sigma_{D i s .}$ is the dislocation strengthening part.

The solid-solution hardening of the Nickel-base superalloy matrix contribute to the overall strength by the effect from each alloying element, which is proportional to the square root of individual alloying concentration $\sqrt{C_{i}}$, as:

$\Delta \sigma_{S S}=f_{\gamma} \sum_{i}\left(\frac{d \sigma}{\sqrt{d C_{i}}} \sqrt{C_{i}}\right)$

Where $f_{\gamma}$ is the fraction of the $\gamma$ matrix (for $\mathrm{AB}$ sample $f_{\gamma}$ is assumed to be equal to the fraction of cell interior) and $\frac{d \sigma}{\sqrt{d C_{i}}}$ is a strengthening coefficient for each element in the unit of $\mathrm{MPa} /(\mathrm{at} \%)^{1 / 2}$, the values are listed in detail in Roth's et al. work [53]. It gives the result of $\Delta \sigma_{S S}$ to be $586 \mathrm{MPa}, 443 \mathrm{MPa}$, and $342 \mathrm{MPa}$ for $\mathrm{AB}, 1000 \mathrm{HIP}$, and 1210HIP, respectively. Nominal composition of IN738LC was used for calculating the $\Delta \sigma_{S S}$ of AB sample, while $\gamma$ phase compositions derivated from thermodynamic calculations (ThermoCalc TCNI8 database) were used for $1000 \mathrm{HIP}$ and 1210HIP.

Additionally, the total yield strength is the sum of Peierls stress (crystal lattice resistance), $\sigma_{0}$, and yield strength increment $\Delta \sigma_{y}$. We take $\sigma_{0}=37 \mathrm{MPa}$ [53] for pure Nickel at room temperature to conclude the calculation. According to the analysis, the yield strength is determined as $1101 \mathrm{MPa}, 1276 \mathrm{MPa}$, and $905 \mathrm{MPa}$ for the $\mathrm{AB}, 1000 \mathrm{HIP}$, and $1210 \mathrm{HIP}$, respectively, with the corresponding microstructural parameters. Meanwhile, the average measured yield strength value is $1084 \mathrm{MPa}, 1307 \pm 19 \mathrm{MPa}$, and $901 \pm 19 \mathrm{MPa}$ for the AB, 1000HIP, 
(a)

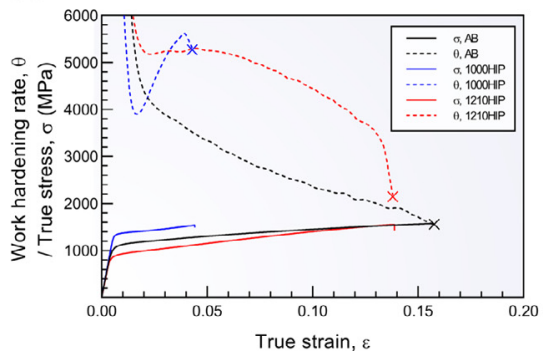

(b)

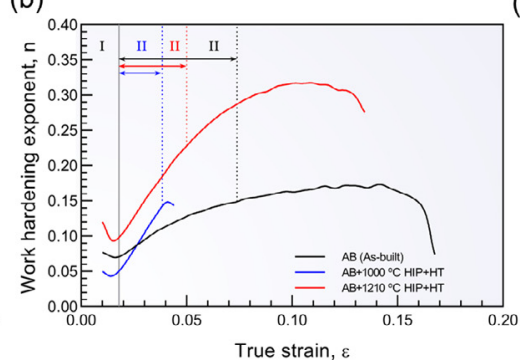

(c)

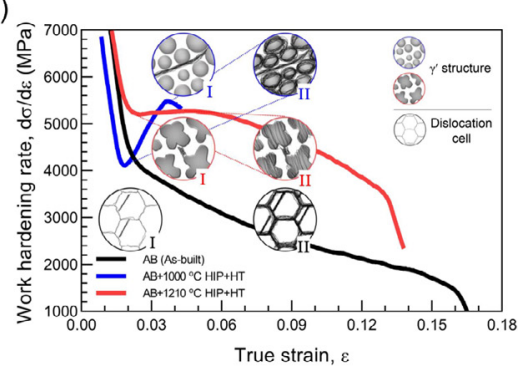

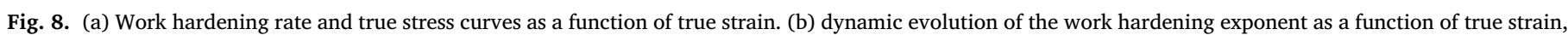
(c) schematic illustration of the typical work-hardening curves for AM processed IN738LC alloys with different microstructures.

and 1210 HIP, respectively, as shown in Table 1 . The experimental and calculated yield strength values are thus in a very good agreement with each other.

\subsection{On the work hardening response}

Fig. 8(a) combine the work hardening rate, $\theta$, and true stress curves as a function of true strain for all of the $\mathrm{AB}, 1000 \mathrm{HIP}$ and $1210 \mathrm{HIP}$ specimens. By analyzing the work hardening behavior of the three samples, multiple-stage work hardening behaviors are distinguishable. At the work hardening stage I, i.e. the 'easy glide' stage [46], the work hardening rate (assessed at true stress over true strain, $d \sigma / d \varepsilon$ ) of $1000 \mathrm{HIP}$ sample dramatically drops to the lowest value among the three samples, where the $A B$ sample has the intermediate value and 1210HIP keeps the highest value. At the small strain level in work hardening stage I, the work hardening rate value is reflected by the difficulty of dislocation activity, i.e., the dislocation mean free path, $\Lambda$. Specifically, the $1000 \mathrm{HIP}$ sample presents the lowest work-hardening rate due to its largest $\Lambda$, which is approximately equal to the continuous $\gamma$ channel length $(>1000 \mathrm{~nm})$ between the spherical $\gamma^{\prime}$, as inferred of micrographs in Fig. 7(a1). In the AB sample, the dislocation mean free path is mainly determined by the size of dislocation cells $(\sim 423 \mathrm{~nm}$ for the average cellular size), resulting in the intermediate work hardening value. Moreover, for the 1210HIP sample, owing to the restricted slip plane direction, the $\Lambda$ has the shortest value equals to its average $\gamma$ channel spacing around $225 \mathrm{~nm}$, leading to the highest work hardening value.

At around $1.8 \%$ true strain, the stage II work hardening, i.e. the linear work hardening rate region, occurs, which has the biggest contribution to the strength. At stage II, the 1000HIP sample shows rapid increase in work hardening rate until reaching $\sim 3.9 \%$ of true strain. The other post-thermal treated sample 1210HIP displays a work hardening rate plateau at $\sim 5100 \mathrm{MPa}$ till $\sim 5 \%$ of true strain. On the other hand, the $\mathrm{AB}$ sample have a smooth evolution of the work hardening rate up to $\sim 7.4 \%$ of true strain and similar behavior in the following work-hardening stage.

Furthermore, the instantaneous work hardening exponent, $n$, (derived from Hollomon equation, $\sigma=K \varepsilon^{n}$ ) as a function of true strain (Fig. 8(b)) is used to assess the work hardening behavior with multiple hardening mechanism [50]. It can be noted that the higher $\mathrm{n}$ value gives the higher work hardening behavior. At identical true strain levels, the 1000HIP and 1210HIP samples present similar increase of the work-hardening exponent because of the similar hardening effects by the secondary $\gamma^{\prime}$ phase precipitation strengthening.

Here we introduce a dimensionless index, $W$, to qualitatively describe the work hardening degree, which can be written as:

$W=\int_{\varepsilon_{I I}}^{\varepsilon_{\text {frac. }}} n d \varepsilon$

Where, $\varepsilon_{I I}$ and $\varepsilon_{\text {frac. }}$ are the true strain at the start of work hardening stage II and true strain at the fracture, respectively. $n$ is the work hardening exponent. Then, by integrating $n$ over $\varepsilon$ in the dynamic evolution of the work hardening exponent curve, the $W$ is calculated to be $2.16 \%$, $0.28 \%$ and $3.02 \%$ for $\mathrm{AB}, 1000 \mathrm{HIP}$ and $1210 \mathrm{HIP}$ specimen, respectively.

It should be mentioned that both post-thermal treated samples underwent premature failures. As shown in the work hardening curves in Fig. $8(\mathrm{a})$, the $1000 \mathrm{HIP}$ and $1210 \mathrm{HIP}$ samples fractured within its uniform plastic regime, before the $\theta$ reaches to the equal amount as true stress, as defined by the Considère instability criterion [54]. Interestingly, in general, higher work hardening rate would keep the deformation proceeding and thus ensure a higher tensile elongation, or more uniform plasticity before necking. As reported by Yang et al. [50], good ductility was achieved by sustaining higher work hardening rate during the plastic deformation process in a multicomponent intermetallic nanoparticle enhanced alloy system. Moreover, in twinning-induced plasticity steels, higher work hardening rate caused by twinning interaction also results in the higher ductility [55]. As well as in the mediumor high- entropy alloy systems, the high work hardening capacity induced higher ductility is well used for the interpretation of temperature dependence elongation differences [56]. On the other hand, the intermetallic precipitates also have a strong effect on the embrittlement. The double-edge effect of precipitate strengthening is discussed in details in Section 4.3.

To summarize, we analyzed the work-hardening evolution and coupled it with the microstructural parameters for the three specimens as presented in the schematic illustration in Fig. 8(c). At work-hardening stage I, easy glide starts by dislocation motion on the slip systems. The work hardening rate value here is reflected by the difficulty of dislocation activity. In the $\mathrm{AB}$ specimen, the work hardening rate curve (blackdashed curve) keeps decaying within the deformation process. The continuous drop of the work hardening rate represents that dislocation planar slip dominates the plastic deformation. Coming to work hardening stage II, in contrast, the $1000 \mathrm{HIP}$ and $1210 \mathrm{HIP}$ specimens underwent a recovery of work hardening rate after the sharp drop of $\theta$ in work hardening stage I, owing to the significant strengthening effect of the $\gamma^{\prime}$ phase. Beyond Nickel-base superalloy, more specifically, the recovery of work hardening rate is widely found in twinning-induced plasticity (TWIP) and/or transformation-induced plasticity (TRIP) alloys. Briefly, these different categories of work hardening rate recovery is caused by the reduction of dislocation mean free path, $\Lambda$, during plastic deformation $[57,58]$. In TWIP alloys, the newly formed twin boundaries decrease the $\Lambda$, while it is newly formed phase boundaries in TRIP alloys. However, in this study the reason for the recovery of work hardening rate in the 1000HIP sample is due to the dynamic evolution of dislocation motion with respect to the multi-scale deformation places. With the deformation preceding, the $\Lambda$ is reduced by the consumption of the longchain continuous $\gamma$ channels for gliding, then the dislocations bypass the obstacles via dislocation looping in the space between the precipitates.

\subsection{On the conflicting nature of strengthening and ductility reduction}

The tensile ductility of the tested L-PBF IN738LC is profoundly influenced by the strengthening mechanisms in the aforementioned 

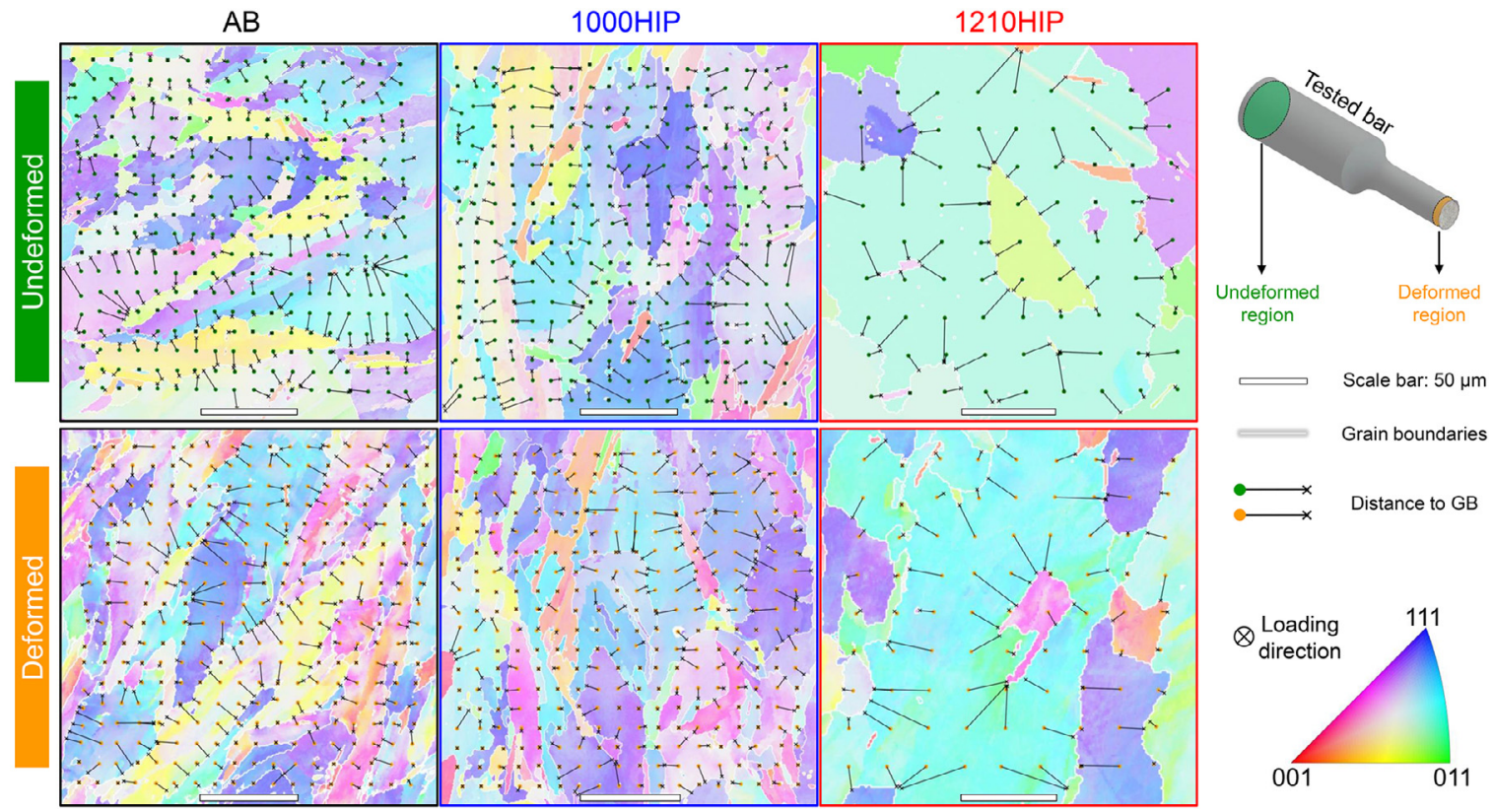

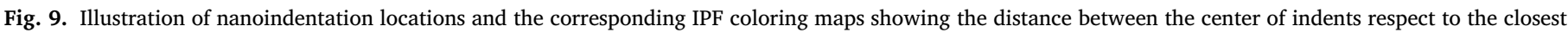
grain boundary. The EBSD-IPF coloring mapping is overlapped on the corresponding nanoindents area after the nanoindentation measurements.

discussions. Moreover, the grain boundaries play a signification role on the plastic deformation. As the results shown from fractography, intergranular cracking characteristics are observed in the two postthermal treated samples. To further reveal the role played by the grain boundaries and bulk grains, we used nanoindentation to identify the mechanical response differences within the localized micron-scale microstructure, as shown in Fig. 9. To fairly compare the evolution of microstructure under the plastic deformation, "undeformed" and "deformed" nanoindentation samples were extracted from the grip section and gauge section, respectively from the identical tested tensile bars for each of the $\mathrm{AB}, 1000 \mathrm{HIP}$, and 1210HIP conditions. Owing to the high load-displacement sensitivity of the nanoindentation test, the local indentation mechanical behavior can be illustrated, which has enabled studies of the grain boundaries mechanical properties $[59,60]$ and local slip resistances [61]. By systematically studying the nanoindentation hardness changes as a function of the distance from the closest grain boundary, the mechanical characteristics of the grain boundary and grain interior regions are reasonably revealed. However, in particular, these kind of investigations have previously focused on mainly simple alloy systems, e.g. Fe-Si steel [62] or pure metals [63]. Furthermore, the studied polycrystalline materials in these investigations [62-64] are all coarse grain with the grain size in the millimeter scale. However, according to the large-scale uncertainty of the complex alloy system and the anomalous fine grain morphology of the L-PBF IN738LC in this study, an indentation matrix was used for a better statistical meaning, where the indentation matrix map is shown in Fig. 9. With the imposed orientation imaging mapping from the EBSD measurement on the nanoindentation area, the grain boundaries with grain boundary misorientation higher than $10^{\circ}$ were marked in color white. To create the distance profile, the distance from the center of each individual indent to its closest grain boundary was measured. As shown in Fig. 9, the round mark indicates the indent and cross mark indicates the corresponding closest grain boundary positions.

Observed from the TEM micrographs in Section 4.1, successive dislocations are nucleated and moved, which controls the plasticity behavior of polycrystalline materials. Furthermore, the operative space of dislocation motion is restricted to certain areas, e.g. mainly the cellular interior for the AB sample and the $\gamma$ channels for the 1000HIP and 1210HIP samples. The cellular boundaries and $\gamma^{\prime}$ phases act as the main strengthen- ing source for the corresponding specimen. By comparing the hardness profile along the distance from GBs in both deformed and undeformed microstructures, the deformation process evolution can be unveiled, as shown in Fig. 10. As depicted in the hardness profile curves, the overall hardness in the deformed microstructure is increased comparing with the undeformed ones. The incremental hardness increase between undeformed and deformed microstructures are consistent with the estimated work hardening degree as calculated by Eq. (11), i.e., the 1210HIP has the largest work hardening degree (3.02\%), AB is in the middle $(2.16 \%)$ and less work hardening occur in 1000HIP $(0.28 \%)$.

From one hand, to achieve the stronger mechanical response, more effective strengthening microstructures are desired. On the other hand, to achieve the ductile properties, more space to accommodate the plasticity is required. For the $\mathrm{AB}$ sample, the undeformed microstructure exhibits stronger (higher hardness value) grain boundaries but weaker grain interior (lower hardness). After the deformation process, although the overall hardness response increased, the deformed hardness profile along distance from GBs has the similar trend compared with the undeformed one. According to the comparison between undeformed and deformed microstructural hardness profiles, the deformation is homogeneously distributed across GB and grain interior in AB samples. Additionally, the microstructure of the grain interior of the $A B$ sample is mainly a cellular structure, where the cellular interior has the higher fraction ( $21 \%$ cellular walls but $79 \%$ cellular interior). The large proportion of cellular interior area ensure the higher potential for $A B$ sample to accommodate the plasticity.

In contrast, the mechanical response of the grain boundaries and the grain interior appear different for the 1000HIP and 1210HIP samples, as shown in Fig. 10(b) and (c). Even though the overall hardness value of the deformed microstructure has increase compared to the undeformed state, heterogeneous deformation occur between the grain boundary (GB) and grain interior. In the undeformed microstructure, both $1000 \mathrm{HIP}$ and $1210 \mathrm{HIP}$ samples has a stronger GB region than the grain interior region, demonstrating a similar hardness profile as in the $\mathrm{AB}$ undeformed microstructure. With the deformation proceeds, the movement of dislocations in the grain bulk encounters the $\gamma^{\prime}$ phase, which has an effective hinderance effect on the mobile dislocations. These mobile dislocations are restricted to the $\gamma$ matrix, resulting in the difficulty to push the dislocations to the grain boundaries. Conse- 

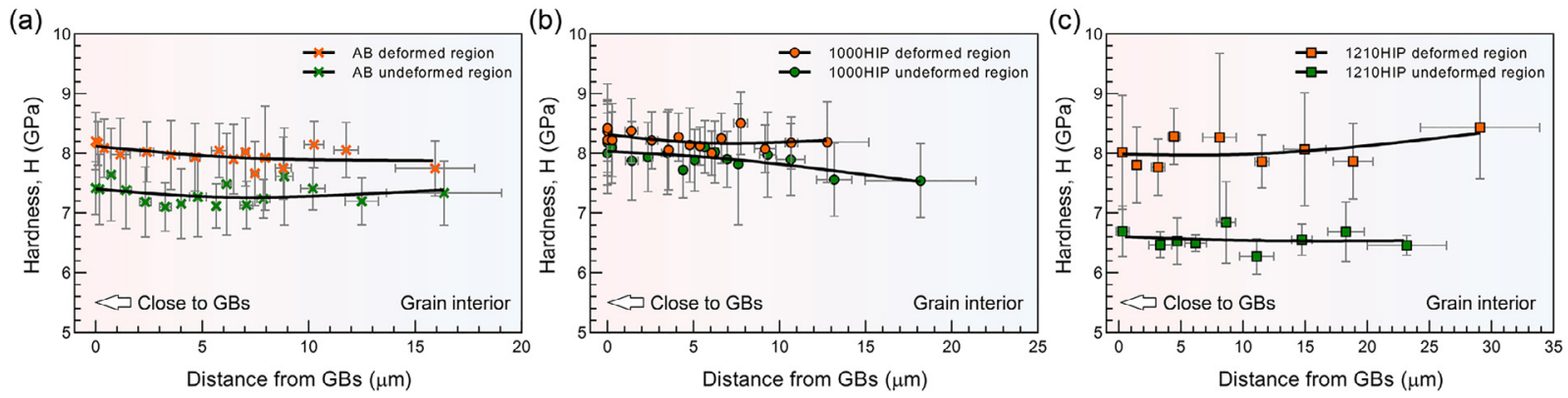

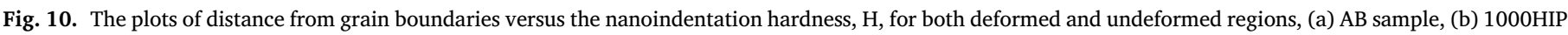
sample, and (c) 1210HIP sample.

quently, the grain interior region shows a higher degree of hardening owing to the larger amount of stored dislocations. This heterogenous deformation process leads to a different hardness distribution across GB and grain interior in the deformed microstructures, i.e. the hardness value in grain interior region is close to or greater than the GB region, as shown in Fig. 10(b) and (c). Once the space for the dislocation motion in the grain interior is limited by the stored dislocations, the grain boundaries have to act as the sites for mediating plasticity and ductility is reduced.

In general, the mechanisms for GB-mediated plasticity are GB sliding and grain rotation [65]. Indeed, in our previous study [66], GB sliding could substitute as the dominant deformation accommodation mechanism in L-PBF IN738LC superalloys at the elevated temperature and under slow strain rate conditions. However, it has been proposed that the GB-mediated plasticity at relatively low temperature requires that the grain size is reduced to a critical value, e.g. 11-22 nm for Nickel [67]. Based on the discussion, under the test condition in study, the coarse GBs (comparing with nanograins) of L-PBF IN738LC superalloys have poor ability for plasticity mediation. It means that in the 1000HIP and 1210 HIP sample, once the $\gamma$ matrix in the grain interior is highly occupied by the impeded dislocations, to maintain the plastic flow, the grain boundaries debones, which leads to the intergranular failure as proofed in Fig. 4. By comparison between 1000HIP and 1210HIP sample, the $1000 \mathrm{HIP}$ has lower tensile elongation. It can be well interpreted by the higher strengthening effect of finer $\gamma^{\prime}$ in 1000HIP than 1210HIP, according to the mechanical evidence of recovery of work hardening rate curve in Fig. 9, and deformation substructure evidence of higher dislocation density in $\gamma$ channel than 1210HIP in Fig. 7.

\section{Conclusions}

We successfully demonstrated that the Nickel-base superalloy IN738LC produced by L-PBF yields simultaneously enhanced strength and ductility compared to its conventional cast counterparts reported in literature, while post AM-processes combining HIP and standard heat treatment result in the typical strength-ductility trade-off for $\gamma-\gamma^{\prime}$ alloys. The following conclusion can be drawn:

1. The as-built microstructure is composed of weakly textured polycrystalline grains with heterogeneous dislocations, i.e., a high density of cellular dislocation structures. The cellular wall structures are confirmed to effectively hinder the dislocation movements, which highly strengthened the alloy. While in the $\gamma^{\prime}$ strengthened samples, the major strengthening effect comes from the precipitation hardening. By taking grain boundary, solid solution, precipitation and dislocation hardening into consideration, the calculated yield strength is $1101 \mathrm{MPa}, 1276 \mathrm{MPa}$, and $905 \mathrm{MPa}$ for AB, 1000HIP, and 1210HIP samples respectively. The results agree well with the experimentaly determined yield strength.

2. Under the room temperature deformation process, the primary deformation mechanism is dislocation planar slip within the cellular interior in the as-built sample while dislocation looping around the $\gamma^{\prime}$ precipitates in post-thermal treated samples.

3. Work hardening is correlated to the dislocation mean free paths, where the recovery of work hardening rate in $\gamma-\gamma^{\prime}$ Nickel-base superalloys is caused by an evolution of the multi-scale deformation volume. When the dislocation mean free paths are reduced after the easy glide within the continuous $\gamma$ channels, a recovery of the work hardening rate occurs.

4. Under the room temperature tensile condition, the plastic deformation is mediated by local dislocation activities. The suitable size of the precipitates leads to an obvious positive increase of yield strength by impeding the dislocation motion. This results in a larger degree of hardening in the grain bulk area, where the precipitates in the grain interior region barely allow the dislocation to be pushed to the grain boundaries. Once the grain interior $\gamma$ channel being rapidly occupied by stored dislocations, the early stage embrittlement occurs.

\section{Declaration of Competing Interest}

No potential conflict of interest was reported by the authors.

\section{Acknowledgment}

This work was supported by the Swedish Agency for Innovation Systems, (Vinnova grant 2016-05175 and 2018-00804); faculty grant from Linköping University (SFO-MAT-LiU\#2009-00971); and center for Additive Manufacture - Metal (CAM2). The authors acknowledge K. Minet and A. Shaikh from EOS Finland Oy, Dr. A. Eklund from Quintus Technologies $\mathrm{AB}$, Dr. H. Brodin from Siemens Industrial Turbomachinery $A B$, Prof. E. Hryha from Chalmers University of Technology, and Dr. S. Bengtsson from Höganäs AB for fruitful discussions. JX would like to thank Dr. D. Deng for the helpful discussions.

All data included in this study are available from the corresponding author on reasonable request.

\section{Supplementary materials}

Supplementary material associated with this article can be found, in the online version, at doi:10.1016/j.mtla.2020.100657.

\section{References}

[1] J.J. Moverare, S. Johansson, R.C. Reed, Deformation and damage mechanisms during thermal-mechanical fatigue of a single-crystal superalloy, Acta Mater. 57 (2009) 2266-2276, doi:10.1016/j.actamat.2009.01.027.

[2] T.M. Pollock, R.D. Field, Chapter 63 Dislocations and high-temperature plastic deformation of superalloy single crystals, in: Dislocations in Solids, Elsevier B.V., 2002 pp. 547-618.

[3] T.M. Pollock, S. Tin, Nickel-based superalloys for advanced turbine engines: chemistry, microstructure and properties, J. Propuls. Power. 22 (2006) 361-374, doi:10.2514/1.18239.

[4] L. Kovarik, R.R. Unocic, J. Li, P. Sarosi, C. Shen, Y. Wang, M.J. Mills, Microtwinning and other shearing mechanisms at intermediate temperatures in Ni-based superalloys, Prog. Mater. Sci. 54 (2009) 839-873, doi:10.1016/j.pmatsci.2009.03.010. 
[5] R.C. Reed, J.J. Moverare, A. Sato, F. Karlsson, M. Hasselqvist, A new single crystal superalloy for power generation applications, in: Superalloys 2012, John Wiley \& Sons, Inc., Hoboken, NJ, USA, 2012, pp. 197-204, doi:10.1002/9781118516430.ch22.

[6] J.S. Van Sluytman, T.M. Pollock, Optimal precipitate shapes in nickel-base $\gamma-\gamma^{\prime}$ alloys, Acta Mater. 60 (2012) 1771-1783, doi:10.1016/j.actamat.2011.12.008.

[7] F. Zhang, L.E. Levine, A.J. Allen, M.R. Stoudt, G. Lindwall, E.A. Lass, M.E. Williams, Y. Idell, C.E. Campbell, Effect of heat treatment on the microstructural evolution of a nickel-based superalloy additive-manufactured by laser powder bed fusion, Acta Mater. 152 (2018) 200-214, doi:10.1016/j.actamat.2018.03.017.

[8] D. Deng, R.L. Peng, H. Brodin, J. Moverare, Microstructure and mechanical properties of Inconel 718 produced by selective laser melting: sample orientation dependence and effects of post heat treatments, Mater. Sci. Eng. A 713 (2018) 294-306, doi:10.1016/j.msea.2017.12.043.

[9] A.R. Balachandramurthi, J. Olsson, J. Ålgårdh, A. Snis, J. Moverare, R. Pederson, Microstructure tailoring in electron beam powder bed fusion additive manufacturing and its potential consequences, Results Mater. 1 (2019) 100017, doi:10.1016/j.rinma.2019.100017.

[10] D. Deng, J. Moverare, R.L. Peng, H. Söderberg, Microstructure and anisotropic mechanical properties of EBM manufactured Inconel 718 and effects of post heat treatments, Mater. Sci. Eng. A 693 (2017) 151-163, doi:10.1016/j.msea.2017.03.085.

[11] D. Deng, R.L. Peng, J. Moverare, On the dwell-fatigue crack propagation behavior of a high strength superalloy manufactured by electron beam melting, Mater. Sci. Eng. A 760 (2019) 448-457, doi:10.1016/j.msea.2019.06.013.

[12] J. Xu, Z. Huang, L. Jiang, Effect of heat treatment on low cycle fatigue of IN718 superalloy at the elevated temperatures, Mater. Sci. Eng. A 690 (2017) 137-145, doi:10.1016/j.msea.2017.02.104.

[13] G. Lindwall, C.E. Campbell, E.A. Lass, F. Zhang, M.R. Stoudt, A.J. Allen, L.E. Levine, Simulation of TTT curves for additively manufactured Inconel 625, Metall. Mater. Trans. A Phys. Metall. Mater. Sci. 50 (2019) 457-467, doi:10.1007/s11661-018-4959-7.

[14] N.J. Harrison, I. Todd, K. Mumtaz, Reduction of micro-cracking in nickel superalloys processed by selective laser melting: a fundamental alloy design approach, Acta Mater. 94 (2015) 59-68, doi:10.1016/j.actamat.2015.04.035.

[15] V.D. Divya, R. Muñoz-Moreno, O.M.D.M. Messé, J.S. Barnard, S. Baker, T. Illston, H.J. Stone, Microstructure of selective laser melted CM247LC nickel-based superalloy and its evolution through heat treatment, Mater. Charact. 114 (2016) 62-74, doi:10.1016/j.matchar.2016.02.004.

[16] P. Kanagarajah, F. Brenne, T. Niendorf, H.J. Maier, Inconel 939 processed by selective laser melting: effect of microstructure and temperature on the mechanical properties under static and cyclic loading, Mater. Sci. Eng. A 588 (2013) 188-195, doi:10.1016/j.msea.2013.09.025.

[17] K.L. Gasko, G.M. Janowski, B.J. Pletka, The influence of $\gamma-\gamma^{\prime}$ eutectic on the mechanical properties of conventionally cast MAR-M247, Mater. Sci. Eng. A 104 (1988) 1-8, doi:10.1016/0025-5416(88)90400-4.

[18] C. Qiu, X. Wu, J. Mei, P. Andrews, W. Voice, Influence of heat treatment on microstructure and tensile behavior of a hot isostatically pressed nickel-based superalloy, J. Alloys Compd. 578 (2013) 454-464, doi:10.1016/j.jallcom.2013.06.045.

[19] K. Kunze, T. Etter, J. Grässlin, V. Shklover, Texture, anisotropy in microstructure and mechanical properties of IN738LC alloy processed by selective laser melting (SLM), Mater. Sci. Eng. A 620 (2015) 213-222, doi:10.1016/j.msea.2014.10.003.

[20] E. Balikci, A. Raman, R.A. Mirshams, Influence of various heat treatments on the microstructure of polycrystalline IN738LC, Metall. Mater. Trans. A 28 (1997) 19932003, doi:10.1007/s11661-997-0156-9.

[21] S. Ma, D. Brown, M.A.M. Bourke, M.R. Daymond, B.S. Majumdar, Microstrain evolution during creep of a high volume fraction superalloy, Mater. Sci. Eng. A 399 (2005) 141-153, doi:10.1016/j.msea.2005.02.034.

[22] X. Wang, L.N. Carter, B. Pang, M.M. Attallah, M.H. Loretto, Microstructure and yield strength of SLM-fabricated CM247LC Ni-superalloy, Acta Mater. 128 (2017) 87-95, doi:10.1016/j.actamat.2017.02.007.

[23] S. Ghosh, L. Ma, N. Ofori-Opoku, J.E. Guyer, On the primary spacing and microsegregation of cellular dendrites in laser deposited Ni-Nb alloys, Model. Simul. Mater. Sci. Eng. 25 (2017) 065002, doi:10.1088/1361-651X/aa7369.

[24] S.A. Khairallah, A.T. Anderson, A. Rubenchik, W.E. King, Laser powder-bed fusion additive manufacturing: physics of complex melt flow and formation mechanisms of pores, spatter, and denudation zones, Acta Mater. 108 (2016) 36-45, doi:10.1016/j.actamat.2016.02.014.

[25] L.E. Murr, S.M. Gaytan, D.A. Ramirez, E. Martinez, J. Hernandez, K.N. Amato, P.W. Shindo, F.R. Medina, R.B. Wicker, Metal fabrication by additive manufacturing using laser and electron beam melting technologies, J. Mater. Sci. Technol. 28 (2012) 1-14, doi:10.1016/S1005-0302(12)60016-4.

[26] Z.G. Zhu, Q.B. Nguyen, F.L. Ng, X.H. An, X.Z. Liao, P.K. Liaw, S.M.L. Nai, J. Wei, Hierarchical microstructure and strengthening mechanisms of a CoCrFeNiMn high entropy alloy additively manufactured by selective laser melting, Scr. Mater. 154 (2018) 20-24, doi:10.1016/j.scriptamat.2018.05.015.

[27] H. Gruber, Unpublished work. (2020).

[28] M. Cloots, P.J. Uggowitzer, K. Wegener, Investigations on the microstructure and crack formation of IN738LC samples processed by selective laser melting using Gaussian and doughnut profiles, Mater. Des. 89 (2016) 770-784, doi:10.1016/j.matdes.2015.10.027.

[29] F. Bachmann, R. Hielscher, H. Schaeben, Texture analysis with MTEX - free and open source software toolbox, Solid State Phenom. 160 (2010) 63-68, doi:10.4028/www.scientific.net/SSP.160.63.

[30] D. Bouchard, J.S. Kirkaldy, Prediction of dendrite arm spacings in unsteady-and steady-state heat flow of unidirectionally solidified binary alloys, Metall. Mater. Trans. B 28 (1997) 651-663, doi:10.1007/s11663-997-0039-x.
[31] P.A. Hooper, Melt pool temperature and cooling rates in laser powder bed fusion, Addit. Manuf. 22 (2018) 548-559, doi:10.1016/j.addma.2018.05.032.

[32] Y.M. Wang, T. Voisin, J.T. McKeown, J. Ye, N.P. Calta, Z. Li, Z. Zeng, Y. Zhang, W. Chen, T.T. Roehling, R.T. Ott, M.K. Santala, P.J. Depond, M.J. Matthews, A.V. Hamza, T. Zhu, Additively manufactured hierarchical stainless steels with high strength and ductility, Nat. Mater. 17 (2018) 63-71, doi:10.1038/nmat5021.

[33] O.M.D.M. Messé, R. Muñoz-Moreno, T. Illston, S. Baker, H.J. Stone, Metastable carbides and their impact on recrystallisation in IN738LC processed by selective laser melting, Addit. Manuf. 22 (2018) 394-404, doi:10.1016/j.addma.2018.05.030.

[34] C. Qiu, H. Chen, Q. Liu, S. Yue, H. Wang, On the solidification behaviour and cracking origin of a nickel-based superalloy during selective laser melting, Mater. Charact. 148 (2019) 330-344, doi:10.1016/j.matchar.2018.12.032.

[35] Alloy IN-738 Technical Data, The International Nickel Company, Inc, New York, 1981, https://www.nickelinstitute.org/media/1709/in_738alloy_preliminarydata 497_.pdf.

[36] R.T.W. Charles Biondo, J. Page Strohl, J.W. Samuelson, G.E. Fuchs, S.T. Wlodek, NICKEL-BASE Alloy for Gasturbine Applications, US 2010/0080729 A1, 2010.

[37] E. Balikci, R. Mirshams, A. Raman, Fracture behavior of superalloy IN738LC with various precipitate microstructures, Mater. Sci. Eng. A 265 (1999) 50-62, doi:10.1016/S0921-5093(99)00012-X.

[38] E.I. Galindo-Nava, L.D. Connor, C.M.F. Rae, On the prediction of the yield stress of unimodal and multimodal $\gamma^{\prime}$ Nickel-base superalloys, Acta Mater. 98 (2015) 377390, doi:10.1016/j.actamat.2015.07.048.

[39] E. Nes, Modelling of work hardening and stress saturation in FCC metals, Prog. Mater. Sci. 41 (1997) 129-193, doi:10.1016/S0079-6425(97)00032-7.

[40] I. Karaman, H. Sehitoglu, H... Maier, Y. Chumlyakov, Competing mechanisms and modeling of deformation in austenitic stainless steel single crystals with and without nitrogen, Acta Mater. 49 (2001) 3919-3933, doi:10.1016/S1359-6454(01)00296-8.

[41] B.B. He, B. Hu, H.W. Yen, G.J. Cheng, Z.K. Wang, H.W. Luo, M.X. Huang, High dislocation density-induced large ductility in deformed and partitioned steels, Science 357 (2017) 1029-1032, doi:10.1126/science.aan0177.

[42] Z. Cheng, H. Zhou, Q. Lu, H. Gao, L. Lu, Extra strengthening and work hardening in gradient nanotwinned metals, Science 362 (2018) eaau1925, doi:10.1126/science.aau1925.

[43] J. Su, D. Raabe, Z. Li, Hierarchical microstructure design to tune the mechanical behavior of an interstitial TRIP-TWIP high-entropy alloy, Acta Mater. 163 (2019) 40-54, doi:10.1016/j.actamat.2018.10.017.

[44] D.L. Holt, Dislocation cell formation in metals, J. Appl. Phys. 41 (1970) 3197-3201, doi:10.1063/1.1659399.

[45] A.W. Thompson, Substructure strengthening mechanisms, Metall. Trans. A 8 (1977) 833-842, doi:10.1007/BF02661564.

[46] U.F. Kocks, H. Mecking, Physics and phenomenology of strain hardening: the FCC case, Prog. Mater. Sci. 48 (2003) 171-273, doi:10.1016/S0079-6425(02)00003-8.

[47] Y.-.K. Kim, J. Choe, K.-.A. Lee, Selective laser melted equiatomic CoCrFeMnNi high-entropy alloy: microstructure, anisotropic mechanical response, and multiple strengthening mechanism, J. Alloys Compd. 805 (2019) 680-691, doi:10.1016/j.jallcom.2019.07.106.

[48] M.R. Staker, D.L. Holt, The dislocation cell size and dislocation density in copper deformed at temperatures between 25 and $700{ }^{\circ} \mathrm{C}$, Acta Metall. 20 (1972) 569-579, doi:10.1016/0001-6160(72)90012-0.

[49] H. Mughrabi, A two-parameter description of heterogeneous dislocation distributions in deformed metal crystals, Mater. Sci. Eng. 85 (1987) 15-31, doi:10.1016/0025-5416(87)90463-0.

[50] T. Yang, Y.L. Zhao, Y. Tong, Z.B. Jiao, J. Wei, J.X. Cai, X.D. Han, D. Chen, A. Hu, J.J. Kai, K. Lu, Y. Liu, C.T. Liu, Multicomponent intermetallic nanoparticles and superb mechanical behaviors of complex alloys, Science 362 (2018) 933-937, doi:10.1126/science.aas8815.

[51] M. McLean, On the threshold stress for dislocation creep in particle strengthened alloys, Acta Metall. 33 (1985) 545-556, doi:10.1016/0001-6160(85)90018-5.

[52] R.W. Kozar, A. Suzuki, W.W. Milligan, J.J. Schirra, M.F. Savage, T.M. Pollock, Strengthening mechanisms in polycrystalline multimodal nickel-base superalloys, Metall. Mater. Trans. A 40 (2009) 1588-1603, doi:10.1007/s11661-009-9858-5.

[53] H.A. Roth, C.L. Davis, R.C. Thomson, Modeling solid solution strengthening in nickel alloys, Metall. Mater. Trans. A 28 (1997) 1329-1335, doi:10.1007/s11661-997-0268-2.

[54] G.E. Dieter, Mechanical Metallurgy, McGraw-Hill, New York, 1988, doi:10.1016/S0016-0032(62)91145-6.

[55] Z.C. Luo, M.X. Huang, Revisit the role of deformation twins on the work-hardening behaviour of twinning-induced plasticity steels, Scr. Mater. 142 (2018) 28-31, doi:10.1016/j.scriptamat.2017.08.017.

[56] G. Laplanche, A. Kostka, C. Reinhart, J. Hunfeld, G. Eggeler, E.P. George, Reasons for the superior mechanical properties of medium-entropy CrCoNi compared to high-entropy CrMnFeCoNi, Acta Mater. 128 (2017) 292-303, doi:10.1016/j.actamat.2017.02.036.

[57] C.L. Yang, Z.J. Zhang, T. Cai, P. Zhang, Z.F. Zhang, Recovery of strain-hardening rate in Ni-Si alloys, Sci. Rep. 5 (2015) 15532, doi:10.1038/srep15532.

[58] Y.Z. Tian, L.J. Zhao, S. Chen, A. Shibata, Z.F. Zhang, N. Tsuji, Significant contribution of stacking faults to the strain hardening behavior of $\mathrm{Cu}-15 \% \mathrm{Al}$ alloy with different grain sizes, Sci. Rep. 5 (2015) 16707, doi:10.1038/srep16707.

[59] S.R. Kalidindi, S.J. Vachhani, Mechanical characterization of grain boundaries using nanoindentation, Curr. Opin. Solid State Mater. Sci. 18 (2014) 196-204, doi:10.1016/j.cossms.2014.05.002.

[60] G. Cheng, K.S. Choi, X. Hu, X. Sun, Determining individual phase properties in a multi-phase Q\&P steel using multi-scale indentation tests, Mater. Sci. Eng. A 652 (2016) 384-395, doi:10.1016/j.msea.2015.11.072. 
[61] S. Pathak, D. Stojakovic, S.R. Kalidindi, Measurement of the local mechanical properties in polycrystalline samples using spherical nanoindentation and orientation imaging microscopy, Acta Mater. 57 (2009) 3020-3028, doi:10.1016/j.actamat.2009.03.008.

[62] S. Pathak, J. Michler, K. Wasmer, S.R. Kalidindi, Studying grain boundary regions in polycrystalline materials using spherical nano-indentation and orientation imaging microscopy, J. Mater. Sci. 47 (2012) 815-823, doi:10.1007/s10853-011-5859-z.

[63] S.J. Vachhani, S.R. Kalidindi, Grain-scale measurement of slip resistances in aluminum polycrystals using spherical nanoindentation, Acta Mater. 90 (2015) 27-36, doi:10.1016/j.actamat.2015.02.017.

[64] S.J. Vachhani, R.D. Doherty, S.R. Kalidindi, Studies of grain boundary regions in deformed polycrystalline aluminum using spherical nanoindentation, Int. J. Plast. 81 (2016) 87-101, doi:10.1016/j.ijplas.2016.01.001.
[65] H. Van Swygenhoven, Grain boundaries and dislocations, Science 296 (2002) 66-67, doi:10.1126/science.1071040.

[66] J. Xu, H. Gruber, D. Deng, R.L. Peng, J.J. Moverare, Short-term creep behavior of an additive manufactured non-weldable Nickel-base superalloy evaluated by slow strain rate testing, Acta Mater. 179 (2019) 142-157, doi:10.1016/j.actamat.2019.08.034.

[67] Z. Shan, et al., Grain boundary-mediated plasticity in nanocrystalline nickel, Science 305 (2004) 654-657, doi:10.1126/science.1098741. 